\title{
A study on the aerosol optical properties over East Asia using a combination of CMAQ-simulated aerosol optical properties and remote-sensing data via a data assimilation technique
}

\author{
R. S. Park ${ }^{1}$, C. H. Song ${ }^{1}$, K. M. Han ${ }^{1}$, M. E. Park ${ }^{1}$, S.-S. Lee ${ }^{2,3}$, S.-B. Kim ${ }^{2}$, and A. Shimizu ${ }^{4}$ \\ ${ }^{1}$ Advanced Environmental Monitoring Research Center (ADEMRC), School of Environmental Science and Engineering, \\ Gwangju Institute of Science and Technology (GIST), 1 Oryong dong, Buk-gu, Gwangju 500-712, Republic of Korea \\ ${ }^{2}$ National Institute of Meteorological Research, Seoul 156-720, Republic of Korea \\ ${ }^{3}$ School of Earth and Environmental Sciences, Seoul National University, Seoul 151-742, Republic of Korea \\ ${ }^{4}$ National Institute for Environmental Studies, 16-2 Onogawa, Tsukuba-City, Ibaraki, 305-8506, Japan
}

Received: 28 May 2011 - Published in Atmos. Chem. Phys. Discuss.: 24 August 2011

Revised: 18 November 2011 - Accepted: 23 November 2011 - Published: 8 December 2011

\begin{abstract}
To more accurately estimate direct radiative forcing (DRF) by aerosols, and better investigate particulate pollution over East Asia, precise calculations of the optical properties of aerosols, such as aerosol optical depth (AOD), single scattering albedo (SSA) and aerosol extinction coefficient $\left(\sigma_{\text {ext }}\right)$, are of primary importance. The aerosol optical properties over East Asia were investigated in this study, based on US EPA Models-3/CMAQ v4.5.1 model simulations. The CMAQ model simulations in this study were improved in several ways compared to those in a previous study (Song et al., 2008). Although the details of the improvements were described in the manuscript, the following points should be emphasized: (1) two data assimilation techniques were employed for producing more accurate AOD products and meteorological fields over East Asia; (2) updated/upgraded emission inventories were used in the CMAQ model simulations with a fine grid resolution of $30 \times 30 \mathrm{~km}^{2}$; and (3) the 4-D particulate composition calculated from the CMAQ model simulations was converted into 3-D or 4-D aerosol optical products, using the Malm and Hand (2007) algorithm with significant further modifications. The results from the CMAQ model simulations (without assimilation) showed great improvements compared to those from a previous study. For example, in terms of the regression coefficients $(R), R$ values were increased from $0.48-0.68$ (previous study) to $0.62-0.79$ (this study). The monthly-averaged CMAQ-simulated single scattering albedo (SSA) also agreed
\end{abstract}

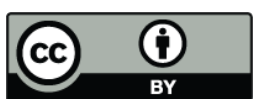

Correspondence to: C. H. Song (chsong@gist.ac.kr) well with the AERONET SSA, with the exceptions of the Hong Kong and Taipei sites, where the air qualities were strongly influenced by active biomass burning events from January to April. There were also excellent matches between the vertical profiles of the CMAQ-simulated $\sigma_{\text {ext }}$ and LIDAR-retrieved $\sigma_{\text {ext }}$. It was also found that the contributions of $\left(\mathrm{NH}_{4}\right)_{2} \mathrm{SO}_{4}$ during summer, $\mathrm{NH}_{4} \mathrm{NO}_{3}$ during winter, sea-salt particles during winter and dust particles during spring to the total AOD were large over East Asia. In particular, the largest contribution of $\mathrm{NH}_{4} \mathrm{NO}_{3}$ to the total AOD was found over East Asia during winter. Therefore, it was suggested that this contribution of $\mathrm{NH}_{4} \mathrm{NO}_{3}$ should not be neglected. In order to produce more accurate AOD products, the CMAQ-simulated AODs were further assimilated with the MODIS-retrieved AODs. Both of the assimilated and AERONET AODs were better correlated with each other than the CMAQ-simulated and AERONET AODs. The obvious benefits from this study would be that with these improved aerosol optical properties, the particulate pollution (e.g. AOD can be served as a proxy to $\mathrm{PM}_{2.5}$ or $\mathrm{PM}_{10}$ ) and DRF by aerosols over East Asia can be more satisfactorily investigated in future.

\section{Introduction}

The importance of the roles of aerosols in global climate change and particulate pollution has been discussed for several decades. Aerosols affect the global radiation budget directly by scattering or absorbing solar radiation, and indirectly by altering the properties of clouds and the efficiency

Published by Copernicus Publications on behalf of the European Geosciences Union. 
of precipitation (Twomey et al., 1984; Coakley and Cess, 1985; Charlson et al., 1991; Rosenfeld, 2000; Kaufman et al., 2002; Ramanathan et al., 2007). Furthermore, the aerosol optical depth (AOD) is empirically well-correlated with $\mathrm{PM}_{2.5}$ and/or $\mathrm{PM}_{10}$; therefore, the ratios of the $\mathrm{AOD}$ to particulate concentrations have been used to estimate the spatial distributions of $\mathrm{PM}_{2.5}$ and/or $\mathrm{PM}_{10}$ at surface levels (e.g. Wang and Christopher, 2003; Kacenelenbogen et al., 2006; van Donkelaar et al., 2006; Vidot et al., 2007; Paciorek et al., 2008; Schaap et al., 2009). To better understand and investigate atmospheric aerosols in East Asia, several research campaigns have been conducted in East Asia, including ground-based monitoring, aircraft and ship measurements (e.g. PEM-West A and B, ACE-Asia, and TRACEP). However, such field campaigns have been limited by an inability to completely cover the spatial and temporal variations of aerosol concentrations and aerosol optical properties.

Over the last several decades, satellite-based observations have been developed, which have partially overcome the limitations of field campaigns (cf. King et al., 1999; Singh and Jacob, 2000; Kokhanovsky et al., 2006). However, the spatial and temporal resolutions of satellite observations are not perfectly satisfactory for completely describing the spatio-temporal variations of atmospheric aerosols. Therefore, three-dimensional chemistry-transport modeling (3-D CTM) studies have been introduced and subsequently combined with these satellite observations (e.g. Chin et al., 2002; Song et al., 2008). Although the 3-D CTM can generate aerosol optical products with high spatio-temporal resolutions, it has some limitations in accurately simulating the optical properties of aerosols, due to the various uncertainties related with the emission strength, meteorological fields, and atmospheric chemical and physical processes (e.g. Kinne et al., 2003; Han et al., 2009). In order to reduce these uncertainties in the 3-D CTM simulations, several investigations have recently been conducted, for example: (1) emission rates for several main atmospheric species were intensively evaluated in East Asia by comparing CTM-simulated gasspecies columns with satellite-retrieved gas species columns (e.g. Han et al., 2009, 2011a) and (2) the accuracy of the meteorological fields has been improved by considering, for example, the impacts of the sea surface temperature on the meteorological fields (Park et al., 2011). On the other hand, the algorithm to calculate the aerosol optical properties from the CTM-simulated particulate composition has also been continuously improved (e.g. Malm et al., 1994; Tegen et al., 1996; Malm, 2000; Chin et al., 2002; Conant et al., 2003; Malm and Hand, 2007).

In addition to these investigations, a data assimilation technique has been employed to further improve the accuracy of the optical products of aerosols, combining the 3-D CTM results with satellite observations (Collins et al., 2001; Yu et al., 2003; Adhikary et al., 2008; Chung et al., 2010). The optical properties of aerosols can be improved via data assimilation in two ways: (1) assimilated aerosol optical properties can fully resolve the spatial and temporal variations with the 3D CTM results and (2) the relatively high uncertainty of the CTM-simulated optical properties of aerosols can be reduced via data assimilation with satellite observations.

In this study, the US EPA Model-3/CMAQ v4.5.1 model was used for simulating the aerosol composition and optical properties, such as the aerosol optical depth (AOD), single scattering albedo (SSA) and aerosol extinction coefficient $\left(\sigma_{\text {ext }}\right)$ over East Asia. The CMAQ-simulated AODs were then assimilated with MODIS-retrieved AODs. Although the data assimilation technique was employed for producing more accurate aerosol optical properties, the CMAQ model simulations should also be conducted rigorously to enhance the efficiency of the data assimilation as well as develop an advanced air quality (chemical weather) forecast system over East Asia. Therefore, this study first focused on improving the CMAQ model simulations via several approaches, i.e. (1) the wind fields from MM5 simulations were assimilated with observed QuikSCAT (Quick Scatterometer) wind data; (2) the emission inventories of INTEX-B (for China and North Korea), REAS (for Japan), and CAPSS (for South Korea) were used for the 2006 simulations; (3) for the $\mathrm{NH}_{3}$ and BVOC (Biogenic VOCs) emissions, EDGAR and MOHYCAN-MEGAN emissions, respectively, were used; (4) monthly variations in the $\mathrm{NO}_{\mathrm{x}}, \mathrm{NH}_{3}, \mathrm{NMVOCs}$ and $\mathrm{SO}_{2}$ emissions were also applied; (5) to consider dust generation and transport, the operational ADAM (Asian Dust Aerosol Models) was used; (6) all the MET, emissions, and CMAQ model simulations were carried out with a fine grid resolution of $30 \times 30 \mathrm{~km}^{2}$ for the entire year of 2006; (7) CMAQ v4.5.1 can consider sea-salt particle generation and transport, and also contains an improved SOA formation scheme compared to the previous study (Song et al., 2008); and (8) the 4-D particulate species concentrations obtained from the CMAQ model simulations were converted into the 3-D or 4-D aerosol optical products, using the recently developed Malm and Hand (2007) algorithm with further modifications. Then, the CMAQ-simulated AOD products were assimilated with the MODIS-retrieved AOD. The free parameters for this data assimilation were selected from sensitivity tests to further enhance the efficiency of the data assimilation, assuming seasonal variations of these free parameters. In the sensitivity runs, the assimilation of the optical properties of aerosols with the selected free parameters was evaluated with the AERONET AOD. Together with these accurate optical properties of aerosols over East Asia, the direct radiative forcing (DRF) by aerosols and the particulate pollution (e.g. AOD has frequently been served as a proxy to $\mathrm{PM}_{2.5}$ and/or $\mathrm{PM}_{10}$ ) over East Asia would be expected to be investigated and understood to much greater extents in the future. 


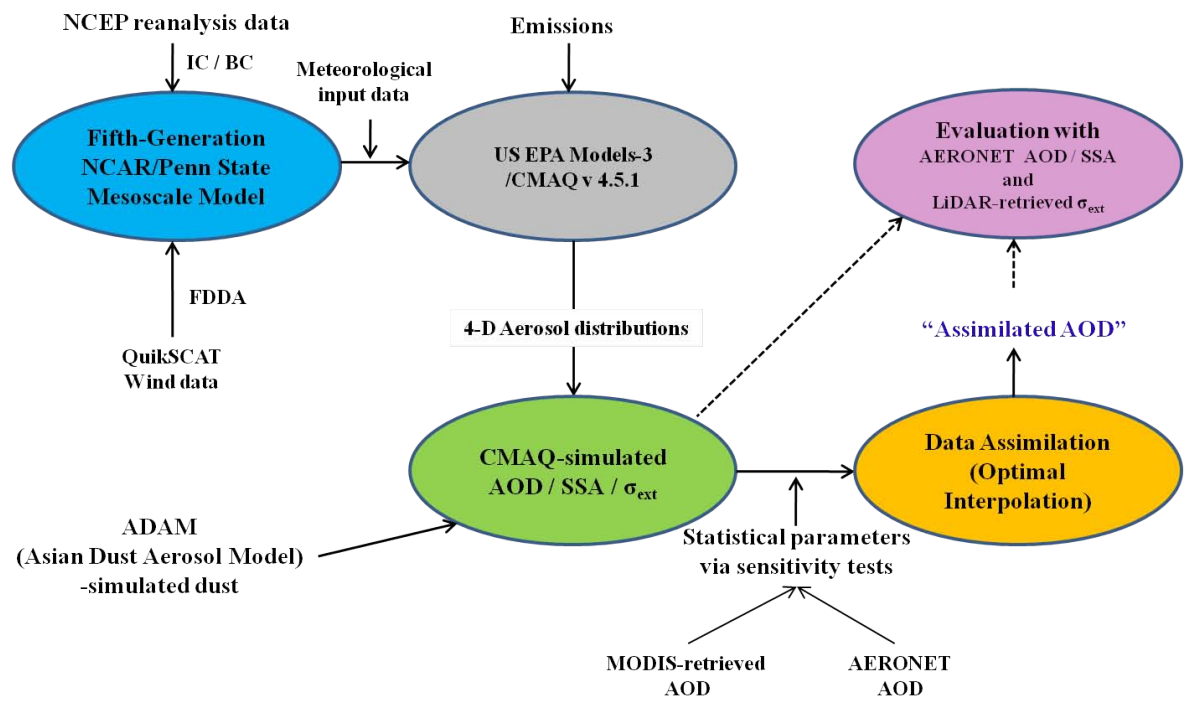

Fig. 1. Flow diagram of the procedures of this study, including: (1) meteorological modeling, (2) US EPA Models-3/CMAQ v4.5.1 modeling, and (3) data assimilations of wind data and the optical properties of aerosols.

\section{Methodology}

In order to reproduce the optical properties of aerosols over East Asia, meteorological and chemistry-transport modeling were carried out. US EPA Model-3/CMAQ v4.5.1 model simulations were conducted with the meteorological fields generated from the MM5 simulations and emission data. In order to convert the 4-D particulate concentrations obtained from the CMAQ model simulations into 3-D or 4$\mathrm{D}$ optical properties of aerosols, the algorithm of Malm and Hand (2007) with further modifications was used. The CMAQ-simulated aerosol optical products were then evaluated using MODIS-, AERONET- and LiDAR (Light Detection And Ranging)-retrieved aerosol optical data. After these evaluations, the CMAQ-simulated AODs were further assimilated with the MODIS-retrieved AODs, and again evaluated with the AERONET AODs. The flow diagram of these works is illustrated in Fig. 1, with the details of the procedures explained, in order, below.

\subsection{Meteorological modeling}

The Fifth-Generation NCAR/Pennsylvania State Meso-scale Model (MM5) was used as a meteorological preprocessor for the CMAQ model simulations. The main characteristics of MM5 have been described in Park et al. (2011). The model domain covers approximately from 90 to $150^{\circ} \mathrm{E}$, and from 20 to $50^{\circ} \mathrm{N}$ in this study (Fig. 2). The horizontal resolutions of the model simulations were $30 \times 30 \mathrm{~km}^{2}$, with fourteen vertical layers (from $1000 \mathrm{hPa}$ to $70 \mathrm{hPa}$ ) in $\sigma$-coordinate employed. Particularly, the vertical resolutions near the surface were finer than those in the upper troposphere, which were used for investigating the surface features in more details.
The simulations were conducted from 00:00 UTC, 1 January to 24:00 UTC, 31 December 2006; the time resolution of the simulations was $30 \mathrm{~s} .2 .5^{\circ} \times 2.5^{\circ} \mathrm{NCEP} / \mathrm{DOE}$ AMIPII Reanalysis data (Reanalysis-2) were used for the initial and boundary conditions (IC/BC). The Grell scheme (Grell et al., 1994), based on the rate of destabilization or quasiequilibrium, was employed for cumulus parameterization, and the MRF Planetary Boundary Layer (PBL) scheme (or Hong-Pan PBL scheme) was applied, which has been shown to be suitable for obtaining high-resolution in the PBL (Hong and Pan, 1996). For an explicit moisture scheme, a mixedphase option was used (Riesner et al., 1998).

Uncertainties of the meteorological modeling are caused by various factors, including the MET model resolution, and the accuracies of the IC/BC, etc. Particularly, the effect of the sea surface temperature (SST) on the meteorological fields has been discussed in several previous studies (Song et al., 2006; Minobe et al., 2008; Park et al., 2011), because there have been serious discrepancies between the SST from in-situ measurements and satellite observations. These discrepancies are generally believed to be caused by instrumental errors and the composition of the satellite data (Donlon et al., 1999; Park et al., 2008). In order to reduce these uncertainties, the QuikSCAT wind data was used employing Four Dimensional Data Assimilation (FDDA). The QuikSCAT wind data was collected from the NASA/JPL SeaWinds Scatterometer aboard the QuikSCAT, and were processed by the NOAA/NESDIS (National Environmental Satellite, Data, and Information Service). 


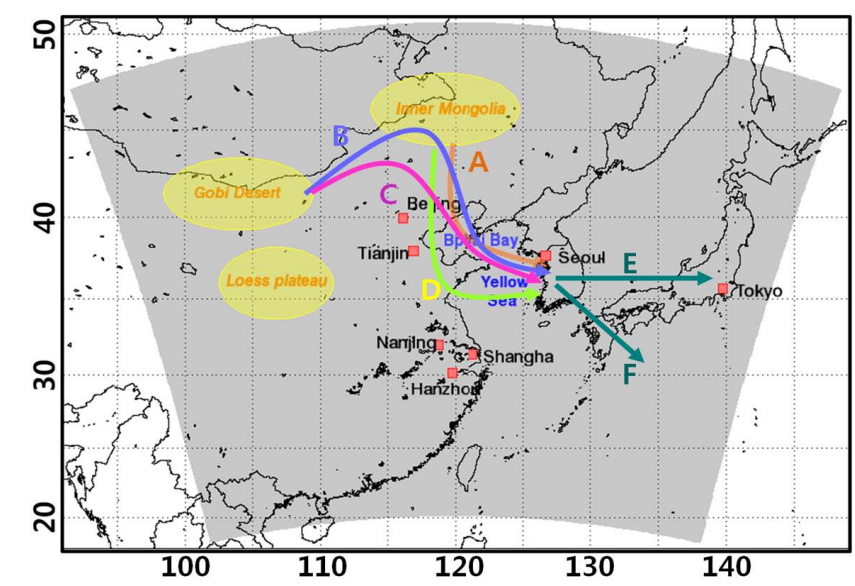

\begin{tabular}{|c|c|c|c|c|}
\hline & Date & Trajectories & & Magnitude $^{*}$ \\
\hline 1 & 15-16 Jan & Inner Mongolia $\rightarrow$ Northeast China $\rightarrow$ Bohai Sea $\rightarrow$ Korea Peninsula & A & 300 \\
\hline 2 & 8-12 Mar & Gobi $\rightarrow$ Inner Mongolia $\rightarrow$ Bohai Sea $\rightarrow$ Korea Peninsula & B & 1017 \\
\hline 3 & 12-14 Mar & Inner Mongolia $\rightarrow$ Northeast China $\rightarrow$ Bohai Sea $\rightarrow$ Korea Peninsula & A & 683 \\
\hline 4 & 24-25 Mar & Gobi $\rightarrow$ Northeast China $\rightarrow$ Bohai Sea $\rightarrow$ Korea Peninsula & C & 209 \\
\hline 5 & 26-28 Mar & $\begin{array}{l}\text { Gobi } \rightarrow \text { Inner Mongolia } \rightarrow \text { Northeast China } \rightarrow \text { Korea Peninsula } \rightarrow \\
\text { Japan Islands }\end{array}$ & $B \rightarrow E$ & 941 \\
\hline 6 & 5-9 Apr & $\begin{array}{l}\text { Gobi } \rightarrow \text { Inner Mongolia } \rightarrow \text { Northeast China } \rightarrow \text { Korea Peninsula } \rightarrow \\
\text { Japan Islands }\end{array}$ & $B \rightarrow F$ & 2298 \\
\hline 7 & 16-20 Apr & $\begin{array}{l}\text { Inner Mongolia } \rightarrow \text { Northeast China } \rightarrow \text { Bohai Sea } \rightarrow \text { Shandong } \\
\text { Peninsula } \rightarrow \text { Korea Peninsula }\end{array}$ & $\mathrm{D}$ & 214 \\
\hline 8 & 22-25 Apr & $\begin{array}{l}\text { Inner Mongolia } \rightarrow \text { Northeast China } \rightarrow \text { Shandong Peninsula } \rightarrow \text { Korea } \\
\text { Peninsula }\end{array}$ & $\mathrm{D}$ & 520 \\
\hline 9 & 27 Apr-1 May & $\begin{array}{l}\text { Gobi } \rightarrow \text { Inner Mongolia } \rightarrow \text { Northeast China } \rightarrow \text { Korea Peninsula } \rightarrow \\
\text { Japan Islands }\end{array}$ & B & 485 \\
\hline
\end{tabular}

* Magnitude represents the maximum concentration of $\mathrm{PM}_{10}\left(\mu \mathrm{g} / \mathrm{m}^{-3}\right)$ over Korean Peninsula for each event.

Fig. 2. Modeling domain (grey-shaded area) of this study, and the trajectories and magnitudes of 9 major dust events that occurred in spring, 2006.

\subsection{Chemistry-transport modeling}

\subsubsection{Model description}

Three-dimensional CTM simulations over East Asia were performed using the US EPA Model-3/CMAQ v4.5.1 model (Byun and Ching, 1999; Byun and Schere, 2006) in order to calculate the 4-D aerosol composition. The aerosol composition, calculated from the CMAQ model simulations, was comprised of three different sized bins: (1) small size-bin $\left(D_{\mathrm{p}}<1 \mu \mathrm{m}\right)$, (2) medium size-bin $\left(1 \mu \mathrm{m}<D_{\mathrm{p}}<2.5 \mu \mathrm{m}\right)$, and (3) large size-bin $\left(D_{\mathrm{p}}>2.5 \mu \mathrm{m}\right)$. The particulate concentration of each species was calculated by the summation of the mass concentrations from these three size-bins. Also, the particulate concentration of each species included the concentrations from different atmospheric processes and precursor sources. For example, the total organic aerosol (OA) concentrations included secondary organic aerosol (SOA) concentrations formed from anthropogenic and biogenic precur- sors as well as primary organic aerosol (POA) concentrations (i.e. $[\mathrm{OAs}]=[\mathrm{POAs}]+[\mathrm{SOAs}]$ ).

The meteorological data for the CMAQ modeling were prepared via the MM5 simulations. The spatial resolution for the CMAQ modeling was $30 \times 30 \mathrm{~km}^{2}$, with fourteen vertical layers, following the grid structures of the MM5 simulations. The period of the CMAQ model simulations was the entire year of 2006, with the daily, monthly and seasonal average values analyzed in this study. The Saprc-99 chemical mechanism for gas-phase chemistry and the aero 4 module for the atmospheric aerosol thermodynamic/dynamic processes were utilized. Other selected schemes were the same as those used previously in Han et al. (2009). Details of the modeling system have also been discussed by Han et al. (2009), and are therefore not reported here.

The domain for the CMAQ model simulations was slightly smaller than that of the MM5 simulations (Fig. 2). The domain, as shown in Fig. 2, features mixtures of 
industrial/commercial/urban centers and agricultural/rural regions, where the strong agricultural and livestock farming activities in the region result in high $\mathrm{NH}_{3}$ emissions (Kim et al., 2006; Song et al., 2008). The region also includes the source regions of Asian dust particles in spring (i.e. Inner Mongolia, Gobi Desert and loess plateau). In addition, the southern margin of the domain (e.g. Hong Kong and Taiwan) is frequently influenced by biomass burning (BB) activities. Due to the complex characteristics of the region, the uncertainty in the emission inventories for this region is relatively high and; thus, the optical properties of aerosols calculated from the CMAQ model simulations can also include such uncertainties. In order to minimize the uncertainties in the emission rates, those of several important atmospheric species were evaluated (and/or constrained) using satellite observations.

\subsubsection{Emissions}

The accuracy of the emission data over East Asia has been discussed, and the emission data have also been evaluated and modified (Zhang et al., 2007; Han et al., 2009, 2011a). Recently, adequate $\mathrm{NO}_{\mathrm{x}}$ and $\mathrm{BVOC}$ emission inventories for the CMAQ model simulations over East Asia have been proposed (Han et al., 2011a). Based on the work of Han et al. (2011a), four anthropogenic emissions and a biogenic emission inventory were used in the Emission-Chemistry Interface Processor (ECIP) for the CMAQ model simulations in this study. To consider the $\mathrm{NH}_{3}$ emissions from China and North Korea, the EDGAR emission inventory was used (see Table 1). For the anthropogenic emissions, the INTEX$\mathrm{B}$, REAS and CAPSS emission inventories were used for China and North Korea, for Japan, and for South Korea, respectively, except in four cases: (1) for the $\mathrm{NH}_{3}$ emissions from China and North Korea, the EDGAR emission inventory was used, because the $\mathrm{NH}_{3}$ emission data obtained from the ACE-ASIA emission inventory is believed to be possibly overestimated (Kim et al., 2006; Song et al., 2008); (2) for the NMVOC emissions from South Korea, the spatial distribution obtained from the INTEX-B emission inventory and the total amounts of NMVOC emissions obtained from the CAPSS emission inventory were combined (Han et al., 2011a); (3) for the isoprene emissions, "MOHYCANMEGAN" (MOHYCAN, a multi-layer canopy module, is incorporated into the MEGAN model) emissions were used for the entire domain; and (4) for the mono-terpene emissions $\left(F_{\text {terp }}\right)$, the ratios of mono-terpene $\left(F_{\text {terp,GEIA }}\right)$ to isoprene $\left(F_{\text {isop,GEIA }}\right)$ from the GEIA emission inventory were used, because the MOHYCAN-MEGAN emissions do not include the mono-terpene emissions, i.e.:

$F_{\text {terp }}=F_{\text {isop,MOHYCAN }} \times \frac{F_{\text {terp,GEIA }}}{F_{\text {isop, GEIA }}}$

The detailed reasons for selecting the emission data have been described in Han et al. (2011a). In addition, the monthly variations in the $\mathrm{NO}_{\mathrm{x}}, \mathrm{SO}_{2}, \mathrm{NH}_{3}$ and $\mathrm{NMVOCs}$ emissions were also applied in this study (regarding this issue, also refer to Han et al., 2011a).

\subsubsection{Dust emissions and transport}

During spring 2006, strong dust events frequently erupted, mostly originating from Inner Mongolia, the Gobi Desert and loess plateau, and were then transported over Northeast China, the Korea Peninsula and Japan (Fig. 2). For example, the dust event that occurred on 5-9 April was extremely strong (refer to its magnitude in Fig. 2), and was transported long-distance to the Yellow Sea, the Korean Peninsula and Japan. The impact of the dust storms on the optical properties of aerosols could be high and should, therefore, be taken into account in the framework of this study. The 4D particulate composition obtained from the CMAQ model simulations did not include the dust concentrations. Therefore, ADAM (Asian Dust Aerosol Model) simulations were conducted over East Asia from March to May, 2006. The ADAM is an operational dust forecast model at the KMA (Korea Meteorological Administration) for East Asia. The model used the outputs of the RDAPS (Regional Data Assimilation and Prediction System), which is a modified version of MM5. The capability of ADAM was evaluated using the dust storms in 2002 over East Asia (In and Park, 2003; Park and In, 2003; Park and Lee, 2004), and was also evaluated in the Dust Model Inter-comparison Project (DMIP) study (Uno et al., 2006). The main features of the ADAM simulations are summarized in Table 2, and the details of the ADAM simulations have previously been reported by Kim et al. (2011), and are therefore not repeated here.

The dust concentrations from the ADAM simulations have simply been added to the 4-D fields of the aerosol composition obtained from the CMAQ model simulations. This simple addition was based on the fact that mineral dust particles over East Asia are usually found to not be greatly chemicallymodified (Maxwell-Meier et al., 2004; Hwang and Ro, 2005; Song et al., 2005, 2007). Frequently, mineral dust particles over East Asia have even been found in an almost fresh form via a single particle chemical analysis (e.g. Zhou et al., 1996; Zhang et al., 2003; Ro et al., 2005). Based on these findings, the dust particles in this study were assumed not to be chemically-aged; it is believed that this assumption could introduce minimal errors.

The CMAQ-simulated AODs along the dust storm pathways noticeably increased after considering the ADAMsimulated dust concentrations. Such an increase in the CMAQ-simulated AOD, caused by the ADAM-simulated dust concentrations, is shown in Supplement Fig. S1, and was evaluated with AERONET AODs (Fig. 3), which are ground measured values; therefore, they have been regarded as "ground truth". The aerosol optical properties acquired from AERONET are described in Sect. 2.5.1. As shown in Fig. 3, the CMAQ-simulated AODs with dust concentrations 
Table 1. Descriptions of the emission inventories used in this study.

\begin{tabular}{|c|c|c|}
\hline Region & Emission inventory & Species \\
\hline \multirow[t]{4}{*}{ China and North Korea } & INTEX-B & $\mathrm{SO}_{2}, \mathrm{NO}_{\mathrm{x}}, \mathrm{NMVOCs}, \mathrm{CO}, \mathrm{CO}_{2}, \mathrm{BC}, \mathrm{OC}$ \\
\hline & EDGAR $^{1}$ & $\mathrm{NH}_{3}$ \\
\hline & MOHYCAN & Isoprene \\
\hline & GEIA & Ratios of mono-terpenes to isoprene $\mathrm{e}^{3}$ \\
\hline \multirow[t]{4}{*}{ South Korea } & CAPSS & $\mathrm{SO}_{2}, \mathrm{NO}_{\mathrm{x}}$, Total NMVOC ${ }^{2}, \mathrm{CO}, \mathrm{NH}_{3}$ \\
\hline & INTEX-B & $\mathrm{NMVOCs}^{2}, \mathrm{CO}_{2}, \mathrm{BC}, \mathrm{OC}$ \\
\hline & MOHYCAN & Isoprene \\
\hline & GEIA & Ratios of mono-terpenes to isoprene ${ }^{3}$ \\
\hline \multirow[t]{3}{*}{ Japan } & REAS & $\mathrm{SO}_{2}, \mathrm{NO}_{\mathrm{x}}, \mathrm{NMVOCs}, \mathrm{CO}, \mathrm{NH}_{3}, \mathrm{CO}_{2}, \mathrm{BC}, \mathrm{OC}$ \\
\hline & MOHYCAN & Isoprene \\
\hline & GEIA & Ratios of mono-terpenes to isoprene ${ }^{3}$ \\
\hline
\end{tabular}

\footnotetext{
1 The emission inventories used in this study were same as those in Han et al. (2011a), except for the $\mathrm{NH}_{3}$ emissions. The ACE-ASIA emission inventory was used for the $\mathrm{NH}_{3}$ emissions in Han et al. (2011a).

2 NMVOC emission data were modified, considering the ratios of NMVOC species to the total NMVOCs from INTEX-B. The total amounts of NMVOC emissions were obtained from the CAPSS emissions (Han et al., 2011a).

3 The mono-terpene emissions were determined from the ratio of mono-terpene to isoprene from the inventory (see Sect. 2.2.2).
}

Table 2. Description of ADAM (Kim et al., 2011).

\begin{tabular}{ll}
\hline Item & Description \\
\hline Meteorological database & RDAPS (Regional Data Assimilation and Prediction System/KMA) \\
Dust emission: & $u *$ (Westphal et al., 1998) + modified Shao et al. (2003)'s minimally and fully \\
threshold velocity or friction velocity & dispersed parent soil particle-size distribution (Park and Lee, 2004) \\
Dust size range (diameter) & $0.2-74.0 \mu \mathrm{m}$ \\
Dust size bins & 11 bins \\
Dust density $\left(\mathrm{g} \mathrm{cm}^{-3}\right)$ & 2.6 \\
Dust particle-size distribution & Log-normal size distribution \\
Land use data & USGS vegetation data with $1 \times 1 \mathrm{~km}^{2}$ resolution \\
Soil texture information & Park and In (2003), In and Park $(2003)$ \\
Roughness & Park and In (2003), In and Park $(2003)$ \\
References & Park and In (2003), In and Park (2003), and Park and Lee (2004) \\
\hline
\end{tabular}

approach those of the AERONET AODs. This was also supported by the statistical analyses presented in Table 3 (the definitions of the statistical values in Table 3 are described in Appendix A).

\subsection{CMAQ-simulated aerosol optical properties}

CMAQ-simulated AOD ( $\left.\tau_{\mathrm{CMAQ}}\right)$ and columnar SSA $\left(\omega_{\mathrm{CMAQ}}\right)$ were calculated from the $4-\mathrm{D}$ particulate concentrations obtained from the US EPA Models-3/CMAQ v4.5.1 model simulations. AOD $(\tau)$, and columnar SSA $(\omega)$ can also be calculated theoretically by integrating the aerosol extinction coefficient $\left(\sigma_{\text {ext }}(z)\right)$ and the aerosol scattering coefficient $\left(\sigma_{\text {scat }}(z)\right)$ with respect to altitude $(z)$, as shown in Eqs. (2-3):

$$
\begin{aligned}
& \tau=\int \sigma_{\text {ext }}(z) \cdot d z \\
& \omega=\frac{\int \sigma_{\text {scat }}(z) \cdot d z}{\int \sigma_{\text {ext }}(z) \cdot d z}
\end{aligned}
$$

The aerosol extinction coefficient $\left(\sigma_{\text {ext }}\right)$, aerosol scattering coefficient $\left(\sigma_{\text {scat }}\right)$, and aerosol absorption coefficient $\left(\sigma_{\text {abs }}\right)$ have the relations shown in Eq. (4), and can be calculated using Eqs. (4-7):

$$
\begin{aligned}
\sigma_{\mathrm{ext}}=\sigma_{\mathrm{scat}} & +\sigma_{\mathrm{abs}} \\
\sigma_{\mathrm{abs}}\left(\mathrm{Mm}^{-1}\right) & \approx\left(1-\omega_{\mathrm{EC}}\right) \times 10.0 \times[\text { Elemental_Carbon }] \\
& +\sum_{i}^{n}\left\{\left(1-\omega_{\text {dust }, i}\right) \times \beta_{i} \times[\text { Dust }]_{i}\right\}
\end{aligned}
$$


Table 3. Statistical values between the CMAQ-simulated and AERONET AODs in spring, 2006.

\begin{tabular}{lcccccc}
\hline AERONET vs. & Number of data & R & RMSE & MNGE & MB & MNB \\
\hline CMAQ (without dust) & 41 & 0.59 & 0.35 & 49.55 & -0.29 & -48.67 \\
CMAQ (with dust) & 41 & 0.70 & 0.31 & 45.32 & -0.19 & -30.09 \\
\hline
\end{tabular}
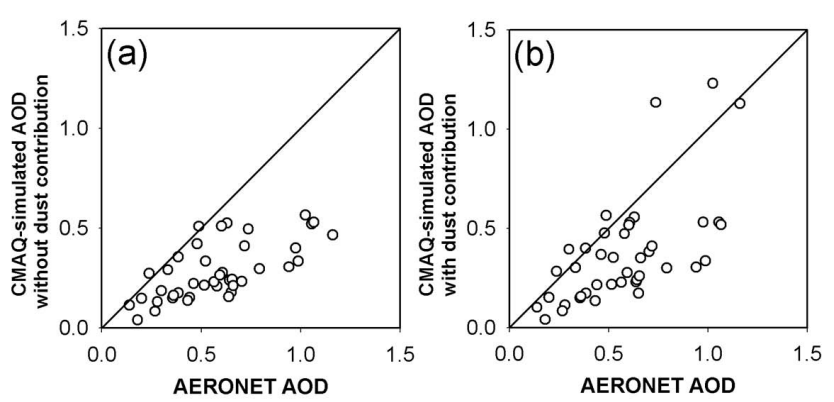

Fig. 3. Scatter plots between CMAQ-simulated and AERONET AODs in spring, 2006: (a) CMAQ-simulated AODs without dust contributions vs. AERONET AODs and (b) CMAQ-simulated AODs with dust contributions vs. AERONET AODs.

$$
\begin{aligned}
& \sigma_{\text {scat }}\left(\mathrm{Mm}^{-1}\right) \approx 3.0 \times f(\mathrm{RH}) \times\left\{\left[\left(\mathrm{NH}_{4}\right)_{2} \mathrm{SO}_{4}\right]+\left[\mathrm{NH}_{4} \mathrm{NO}_{3}\right]\right\} \\
& +\omega_{\mathrm{EC}} \times 10.0 \times[\text { Elemental_Carbon }]+\sum_{i}^{n}\left\{\omega_{\text {dust }, i} \times \beta_{i} \times[\text { Dust }]_{i}\right\} \\
& +4.0 \times[\text { Organic_Mass }]+1.37 \times f_{\mathrm{ss}}(\mathrm{RH}) \times[\text { Sea_Salt }] \\
& f(\mathrm{RH})=b_{0}+b_{1}\left(\frac{1}{1-\mathrm{RH}}\right)+b_{2}\left(\frac{1}{1-\mathrm{RH}}\right)^{2}
\end{aligned}
$$

The main assumption of the above formulas was that $\mathrm{NH}_{4}^{+}$, $\mathrm{SO}_{4}^{2-}$ and $\mathrm{NO}_{3}^{-}$are mixed internally in the urban-derived pollution particles, whereas, other aerosols, such as dust, sea-salt particles and elemental carbon (or black carbon), are mixed externally to the urban-derived pollution particles. Also, urban-derived pollution particles (mainly composed of $\mathrm{NH}_{4}^{+}, \mathrm{SO}_{4}^{2-}$ and $\mathrm{NO}_{3}^{-}$), sea-salt, and organic aerosols are light-scattering, whereas elemental carbon and mineral dust particles have light-absorbing capability. This capability can be considered, using the single scattering albedo of elemental carbon and mineral dust $\left(\omega_{\mathrm{EC}}\right.$ and $\left.\omega_{\mathrm{dust}, i}\right)$, as shown in Eq. (5). Both the $\omega_{\mathrm{EC}}$ and $\omega_{\mathrm{dust}, i}$ values were obtained from Conant et al. (2003) and Tegen et al. (1996), respectively. $f(\mathrm{RH})$ and $f_{\mathrm{ss}}(\mathrm{RH})$ represent the hygroscopic growth factors of $\left(\mathrm{NH}_{4}\right)_{2} \mathrm{SO}_{4}, \mathrm{NH}_{4} \mathrm{NO}_{3}$ and sea-salt particles, respectively, and are a function of the relative humidity $(\mathrm{RH})$. The expression for $f(\mathrm{RH})$ is shown in Eq. (7), and $b_{0}, b_{1}$ and $b_{2}$ in Eq. (7) are the coefficients having seasonal variations (regarding these values, refer to Song et al., 2008). $f_{\mathrm{ss}}(\mathrm{RH})$ is also presented in Table 4. Compared to the previous version of the algorithm proposed by Malm (2000), the current algorithm explicitly considers the contribution of sea-salt particles to the extinction/scattering coefficients. As shown in Eqs. (5-6), the algorithm was further modified to separately consider the scattering and absorption capabilities of mineral dust and elemental carbon. In Eqs. (5-6), $\beta_{i}$ represents the dry mass extinction efficiency (MEE) for the size-bin $i$ of mineral dust particles, and was calculated, based on the data reported by Tegen et al. (1996) at a wavelength of $550 \mathrm{~nm}$. $\mathrm{n}$ denotes the total number of the size-bins of dust particles considered in this study. Estimates of the total ambient $\sigma_{\text {ext }}\left(\mathrm{Mm}^{-1}\right)$ correspond to the values at a wavelength $(\lambda)$ of " $550 \mathrm{~nm}$ ". Other details of the algorithm can be found on the IMPROVE website (http://vista.cira.colostate.edu/ improve/Publications/Reports/2006/2006.htm) and Malm and Hand (2007).

Alternatively, the aerosol extinction coefficient $\left(\sigma_{\text {ext }}\right)$ can also be estimated, using the Mie theory (e.g. Chin et al., 2002, 2004; Bian et al., 2009). However, the Mie-theory based estimations also contain large uncertainties in the prescribed (time-invariant) log-normal size distributions of the particulate species and the mixing state of different types of particles. The dry MEE values estimated from the data of Chin et al. (2002) were 3.8, 10.7, 3.3, and 0.1-1.2 for sulfate, black (elemental) carbon, organic carbon, and sea-salt particles, respectively, at a wavelength of " $500 \mathrm{~nm}$ ". Although these MEE values were estimated at a wavelength of $500 \mathrm{~nm}$, their magnitudes were comparable to those in Eqs. (5-6).

\subsection{MODIS-retrieved AOD}

Satellite-observed data were used for two purposes: (1) the evaluation of the CMAQ model simulations and (2) the data assimilation of the CMAQ-simulated AODs. Satelliteobserved AODs can be retrieved mainly from three instruments: (1) Aura/OMI (Ozone Monitoring Instrument), (2) Aqua/MODIS (Moderate Resolution Imaging Spectroradiometer), and (3) Terra/MODIS. Terra/MODIS-retrieved AODs have been used in the several previous studies (e.g. Yu et al., 2003; Adhikary et al., 2008; Song et al., 2008; Chung et al., 2010). The OMI-retrieved AODs have recently been evaluated, using AERONET and MODIS-retrieved AODs (Curier et al., 2008; Livingston et al., 2009). The accuracy of MODIS-retrieved AODs has been verified in previous studies; whereas, the accuracy of OMI-retrieved AODs 
Table 4. Hygroscopic growth factors for sea-salt particles.

\begin{tabular}{lccccccccc}
\hline RH $(\%)$ & $f_{\mathrm{SS}}(\mathrm{RH})$ & $\mathrm{RH}(\%)$ & $f_{\mathrm{SS}}(\mathrm{RH})$ & $\mathrm{RH}(\%)$ & $f_{\mathrm{SS}}(\mathrm{RH})$ & $\mathrm{RH}(\%)$ & $f_{\mathrm{SS}}(\mathrm{RH})$ & $\mathrm{RH}(\%)$ & $f_{\mathrm{SS}}(\mathrm{RH})$ \\
\hline 0 to 36 & 1.00 & 48 & 2.38 & 60 & 2.69 & 72 & 3.17 & 84 & 4.04 \\
37 & 1.00 & 49 & 2.42 & 61 & 2.73 & 73 & 3.21 & 85 & 4.11 \\
38 & 1.00 & 50 & 2.45 & 62 & 2.78 & 74 & 3.25 & 86 & 4.28 \\
39 & 1.00 & 51 & 2.48 & 63 & 2.83 & 75 & 3.27 & 87 & 4.49 \\
40 & 1.00 & 52 & 2.50 & 64 & 2.83 & 76 & 3.35 & 88 & 4.61 \\
41 & 1.00 & 53 & 2.51 & 65 & 2.86 & 77 & 3.42 & 89 & 4.86 \\
42 & 1.00 & 54 & 2.53 & 66 & 2.89 & 78 & 3.52 & 90 & 5.12 \\
43 & 1.00 & 55 & 2.56 & 67 & 2.91 & 79 & 3.57 & 91 & 5.38 \\
44 & 1.00 & 56 & 2.58 & 68 & 2.95 & 80 & 3.63 & 92 & 5.75 \\
45 & 1.00 & 57 & 2.59 & 69 & 3.01 & 81 & 3.69 & 93 & 6.17 \\
46 & 1.00 & 58 & 2.62 & 70 & 3.05 & 82 & 3.81 & 94 & 6.72 \\
47 & 2.36 & 59 & 2.66 & 71 & 3.13 & 83 & 3.95 & 95 & 7.35 \\
\hline
\end{tabular}

http://vista.cira.colostate.edu/improve/Publications/GrayLit/019_RevisedIMPROVEeq/RevisedIMPROVEAlgorithm3.doc

remain to be fully verified. For example, Curier et al. (2008) reported that OMI-retrieved AODs have good agreements with MODIS-retrieved AODs, but Livingston et al. (2009) suggested that OMI-retrieved AODs from OMAERUV (using near-UV; OMI/Aura Near UV Aerosol Optical Depth and Single Scattering Albedo 1-orbit L2 Swath $13 \times 24 \mathrm{~km}^{2}$ ) and OMAERO (using multiwavelength; OMI/Aura Aerosol Optical Thickness and Single Scattering Albedo 1-orbit L2 Swath $13 \times 24 \mathrm{~km}^{2}$ V003) retrievals were overestimated by factors between 2 to 10 compared with the AERONET and AATS (Ames Airborne Tracking Sunphotometer) AODs. In addition, the AOD products from the OMI instrument were more frequently screened out, due to the relatively large spatial resolution of $13 \times 24 \mathrm{~km}^{2}$. With this relatively large spatial resolution, the AOD retrievals were more frequently interrupted by cloud contamination (the existence of clouds) (Note: the "original" spatial resolution of the MODIS was $0.5 \times 0.5 \mathrm{~km}^{2}$ ). Based on these reports, OMI-retrieved AODs were not used in this study. Instead, MODIS-retrieved AODs were used for the evaluation and data assimilation of CMAQsimulated AODs.

As mentioned above, the MODIS instrument is aboard two NASA Earth Observation System (EOS) platforms: the Terra and Aqua satellites. Both satellites are polar-orbiting, with Terra on a descending orbit (southward), having an equator passing time at about 10:30 local sun time, and with Aqua on an ascending orbit (northward), having an equator passing time at about 13:30 local sun time. In this study, level-3 (L3) daily and monthly global gridded AOD products retrieved from the EOS/Terra MODIS sensor through the NASA C005 (Collection 5) algorithm (Remer et al., 2005; Levy et al., 2007) were used, because Aqua MODISretrieved AODs tend to cover only land areas, with missing data encountered more frequently than with those retrieved via Terra MODIS. The inversion procedure of the C005 algorithm is based on a look-up table (LUT), with four fine modes and five coarse modes; the AODs were retrieved at one wavelength $(\lambda=550 \mathrm{~nm})$. Details of the NASA C005 algorithm are described in the Algorithm Theoretical Basis Document (ATBD, http://modis.gsfc.nasa.gov/data/atbd/ atbd_mod02.pdf). In addition, for the synchronization of the CMAQ-simulated and MODIS-retrieved AODs, the CMAQsimulated AOD was averaged at 10:00 and 11:00 local sun time.

Instead of MODIS AOD, the fine-mode AOD (hereafter fm-AOD) from the MODIS sensors can also be a candidate for this type of study. However, there are relatively large uncertainties in the retrieval procedures of fine-mode fractions (FMFs) from MODIS and AERONET. Because of the uncertainties, the use of fm-AOD was excluded. In addition to the uncertainties in FMFs, if we had used the separate fm-AOD and $\mathrm{cm}$-AOD (coarse-mode AOD), there would have been another difficulty in separately estimating $\mathrm{fm}-\mathrm{SSA}$ and $\mathrm{cm}$ SSA for running the RTM. Therefore, it was assumed that there would not be significant benefits from using the separate fine- and coarse-mode AODs in this study.

\subsection{AERONET and LiDAR aerosol data}

In order to assess the accuracy of the CMAQ-simulated aerosol optical properties, the optical data for aerosols measured from the ground are necessary. The distributions of the CMAQ-simulated AODs and SSAs were compared with the AERONET AODs and SSAs, with the vertical profiles of the aerosol extinction coefficients $\left(\sigma_{\text {ext }}\right)$ compared with the LiDAR-retrieved aerosol extinction coefficients. In this section; therefore, the AERONET and LiDAR-retrieved data are briefly described.

\subsubsection{AERONET data}

AERONET is the federal sunphotometer network, which has been managed by the NASA Goddard Space Flight Center in 


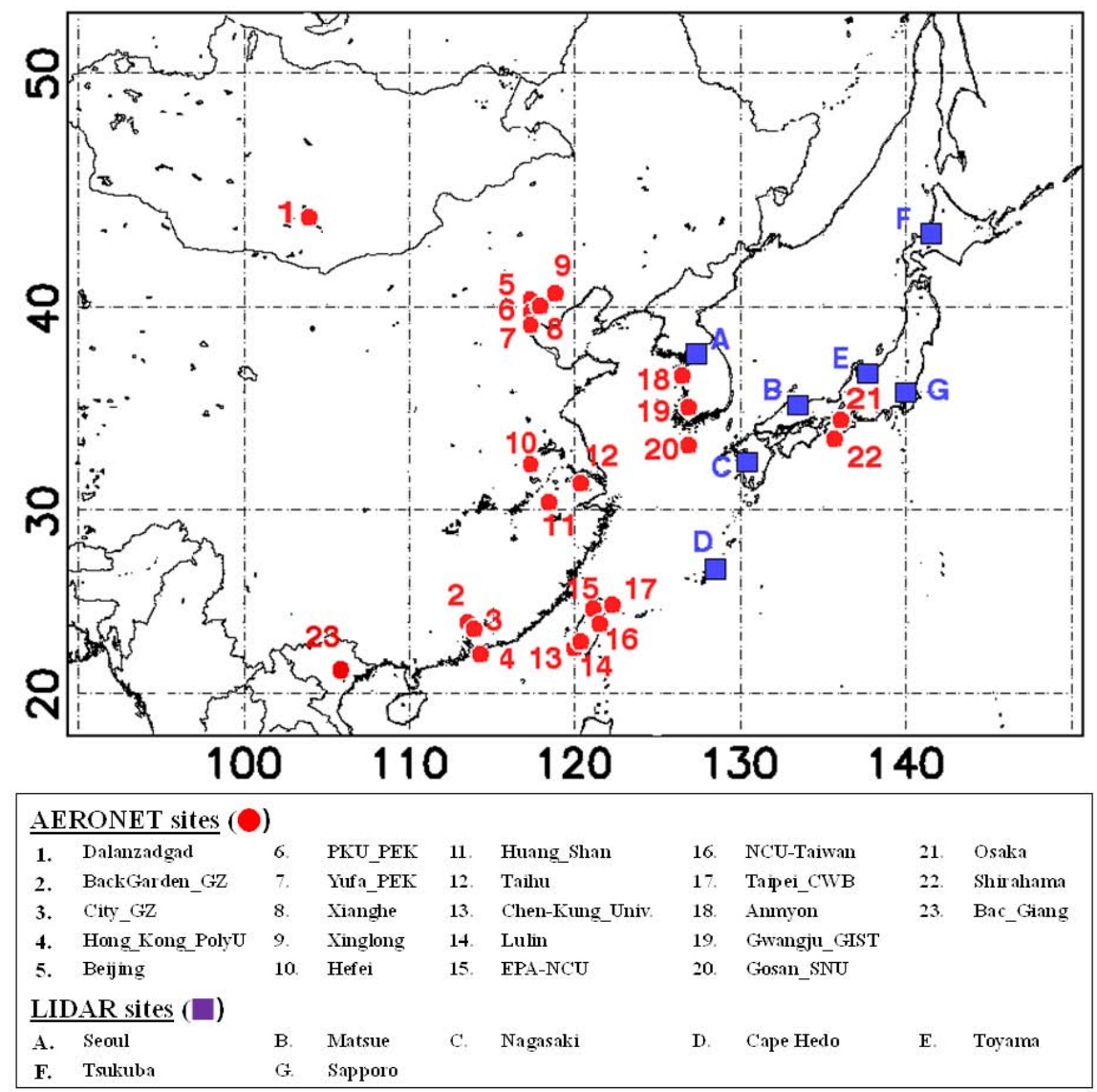

Fig. 4. Locations of the 23 AERONET sites and 7 ADNET (LIDAR network) sites: AERONET AODs were obtained from 22 AERONET sites, except for the Bac_Giang site, and AERONET SSAs were obtained from 10 AERONET sites (Dalanzadgad, Hong_Kong_PolyU, Chen-Kung_Univ., EPA-NCU, Taipei_CWB, Anmyon, Gosan_SNU, Osaka, Shirahama and Bac_Giang sites).

the USA (Holben et al., 1998). Currently, there are 23 available AERONET ground-based stations inside the modeling domain (Fig. 4). AEROENT provides the sunphotometerretrieved total column spectral AODs, SSAs and reflective indices at visible and NIR wavelengths. The spectral AODs and SSAs provided by AERONET are regarded as "ground truth", because they are not affected or interfered by the surface reflectance, due to their own measurement nature. Therefore, the AERONET AODs and SSAs were used for the evaluations of the CMAQ-simulated AODs/SSAs and MODIS-retrieved AODs in this study. Furthermore, the free parameters for the data assimilation were also adjusted by comparisons between the assimilated AODs and AERONET AODs (the details are discussed in Sect. 2.6).

\subsubsection{LiDAR data}

To evaluate the vertical profiles of the aerosol extinction coefficients obtained from the CMAQ model simulations, LiDAR-derived data were used. In East Asia, the optical properties of aerosols, including aerosol extinction coeffi- cients, have been measured at 7 ADNET sites since 2002 (Fig. 4): 5 sites in Japan and 2 sites in South Korea. Three sites (Seoul, Toyama, and Cape Hedo) almost overlap with the AERONET sites. From the 7 sites, the extinction coefficients for non-spherical mineral dust particles and spherical hygroscopic aerosols at $\lambda=532 \mathrm{~nm}$ have been provided (Sugimoto et al., 2008; Shimizu et al., 2010), assuming a fixed LiDAR ratio of $\mathrm{S} 1=50 \mathrm{sr}$ (Shimizu et al., 2010). In this study, the total aerosol extinction coefficients were calculated through the summation of the extinction coefficients by non-spherical mineral dust particles and spherical hygroscopic aerosols, assuming an external mixing of mineral dust and spherical aerosols (Shimizu et al., 2004; Sugimoto et al., 2003). In the ADNET LiDAR measurements, the heights of the cloud base and top were determined, based on the gradients and maximum values of ABC (attenuated backscatter coefficient), the details of which are described in Sugimoto et al. (2008) and Shimizu et al. (2010). The vertical and temporal resolutions of the LiDAR data are $30 \mathrm{~m}$ and $15 \mathrm{~min}$, respectively. Usually, LiDAR-retrieved aerosol optical data below $1 \mathrm{~km}$ are neglected, due to the large uncertainty resulting 
from the low values $(<1.0)$ of the overlap factor, which is affected by the laser light source and distance of the receiving telescope (Velotta et al., 1998; Noh et al., 2009). However, the extinction coefficient data from the ADNET can be corrected using an overlap-correction function developed by the NIES (National Institute of Environmental Studies) in Japan. Therefore, in this study, the LiDAR-retrieved extinction coefficients above $120 \mathrm{~m}$ were used (Shimizu et al., 2011; also see Fig. 7).

\subsection{Data assimilation}

Data assimilation with optimal interpolation (OI) has been used in several studies (Collins et al., 2001; Yu et al., 2003; Adhikary et al., 2008; Chung et al., 2010). In this section, a brief description of the OI is given, with some new procedures for the studies over East Asia. The assimilated AOD products by the $\mathrm{OI}\left(\tau_{\mathrm{m}}^{\prime}\right)$ are defined as follows:

$\tau_{\mathrm{m}}^{\prime}=\tau_{\mathrm{m}}+K\left(\tau_{\mathrm{o}}-H \tau_{\mathrm{m}}\right)$

where $\tau_{\mathrm{o}}$ and $\tau_{\mathrm{m}}$ are the MODIS-retrieved and CMAQsimulated AODs, respectively. $H$ denotes the linear operator for interpolation from the model grid to the location of the observations, and $K$ is the Kalman gain matrix (or Kalman filter). Here, $K$ was based on two main assumptions: (1) the errors have a Gaussian distribution and (2) the errors in the modeled and observed data are not correlated to each other.

$K=B H^{T}\left(H B H^{T}+O\right)^{-1}$

where $B$ and $O$ are the covariance of modeled and observed fields, respectively, and are defined with several free parameters.

$$
\begin{aligned}
& B\left(d_{x}, d_{z}\right)=\left[\left(f_{\mathrm{m}} \tau_{\mathrm{m}}\right)^{2}+\left(\varepsilon_{\mathrm{m}}\right)^{2}\right] \exp \left[\frac{-d_{x}}{2 l_{\mathrm{mx}}^{2}}\right] \exp \left[\frac{-d_{z}}{2 l_{\mathrm{mz}}^{2}}\right] \\
& O=\left[\left(f_{\mathrm{o}} \tau_{\mathrm{o}}\right)^{2}+\left(\varepsilon_{\mathrm{o}}\right)^{2}\right] I
\end{aligned}
$$

where $f_{\mathrm{m}}, \varepsilon_{\mathrm{m}}, d_{x}, d_{z}, l_{\mathrm{mx}}$ and $l_{\mathrm{mz}}$ in Eq. (10) denote the fractional error coefficient, minimum error coefficient, horizontal resolution ( $30 \mathrm{~km}$ in this study), vertical resolution, horizontal correlation length for errors and vertical correlation length for errors in the modeled $\operatorname{AOD}(\tau)$, respectively, and $f_{\mathrm{o}}, \varepsilon_{\mathrm{o}}$ and $I$ in Eq. (11) denote the fractional error coefficient, minimum error coefficient in the observed $\operatorname{AOD}(\tau)$, and a unit matrix, respectively. The free parameters $\left(f_{\mathrm{m}}, f_{\mathrm{o}}\right.$, $\varepsilon_{\mathrm{m}}, \varepsilon_{\mathrm{o}}, l_{\mathrm{mx}}$ and $\left.l_{\mathrm{mz}}\right)$ used in previous studies are summarized in Table 5. Kalman filter is a function of the six free parameters, as well as the CMAQ-simulated and MODIS-retrieved AODs. Consequently, the efficiency of the OI depends on the correct determination of the free parameters, since CMAQsimulated and MODIS-retrieved AODs are unchangeable.

In previous studies, model-simulated AODs were assimilated with the yearly-fixed free parameters over either the regional or global modeling domain (see Table 5); whereas, in this study, the seasonal variations of the free parameters were taken into account over East Asia. The free parameters are sensitive to the accuracy of the modeling products, and the accuracy depends on the uncertainties in the meteorological fields, emissions and CTM simulations. In particular, the uncertainty in the emissions is one of the most important factors affecting the accuracy of the CMAQ-simulated optical properties of aerosols (Song et al., 2008; Han et al., 2009). When the CTM-simulated optical properties of aerosols were calculated from the particulate composition, the dominant particulate species were found to change seasonally (this is discussed in Sect. 3.1). Accordingly, uncertainties in the particulate composition may also change seasonally. Following this reasoning, the accuracy of CMAQ-simulated optical properties of aerosols could also change seasonally. Therefore, the seasonal variations in the free parameters were assumed and determined, when the CMAQ-simulated optical properties of aerosols were assimilated with observations.

Through the sensitivity tests, the best free parameters for the four seasons were determined. The determination of the free parameters was based on an analysis of the monthly CMAQ-simulated AODs. For the sensitivity tests, a statistical parameter of $\chi^{2}$ was introduced:

$\chi^{2}=\sum \frac{\left(\tau_{i, \text { Obs }}-\tau_{i, \text { Modeled }}\right)^{2}}{\tau_{i, \text { Modeled }}}$

where $\tau_{i, \text { Obs }}$ and $\tau_{i, \text { Modeled }}$ represent the observed and model-simulated AODs, respectively. In this formula, a small value of $\chi^{2}$ indicates that the modeled AODs were close to those observed. However, $\chi^{2}$ for the four seasons cannot be directly compared, because the data numbers for the four seasons are different. Therefore, in order to consider the seasonal difference in the number of data available, the formula was divided by the data number:

$\chi^{2}=\frac{1}{N} \sum_{i}^{N}\left[\frac{\left(\tau_{i, \mathrm{AERO}}-\tau_{i, \mathrm{Assim}}\right)^{2}}{\tau_{i, \mathrm{Assim}}}\right]$

where $\tau_{\text {AERO }}$ and $\tau_{\text {Assim }}$ indicate the AERONET AODs and assimilated AODs, respectively. Once $\chi^{2}$ between assimilated AODs and AERONET AODs converged to a minimum value for each season, the free parameters were chosen for that season. The values selected through these procedures are shown in Table 6.

To evaluate the efficiency of the current approach, two assimilated AOD products were compared with AERONET AODs, i.e. (1) the assimilated AODs from the yearly-fixed free parameters and (2) the assimilated AODs from the seasonally-varying free parameters. In the case of the yearlyfixed free parameters, the free parameters, $f_{\mathrm{m}}, f_{\mathrm{o}}, \varepsilon_{\mathrm{m}}$, and $\varepsilon_{\mathrm{o}}$, were set at $0.8,0.2,0$ and 0.05 , respectively. The values of $\chi^{2}$ are shown in Table 6. As shown in Table 6, the assimilated AODs with the seasonally-varying free parameters exhibited better performances for the data assimilation than those with the yearly-fixed free parameters. 
Table 5. Free parameters of the data assimilation and the modeling domains used in the previous studies.

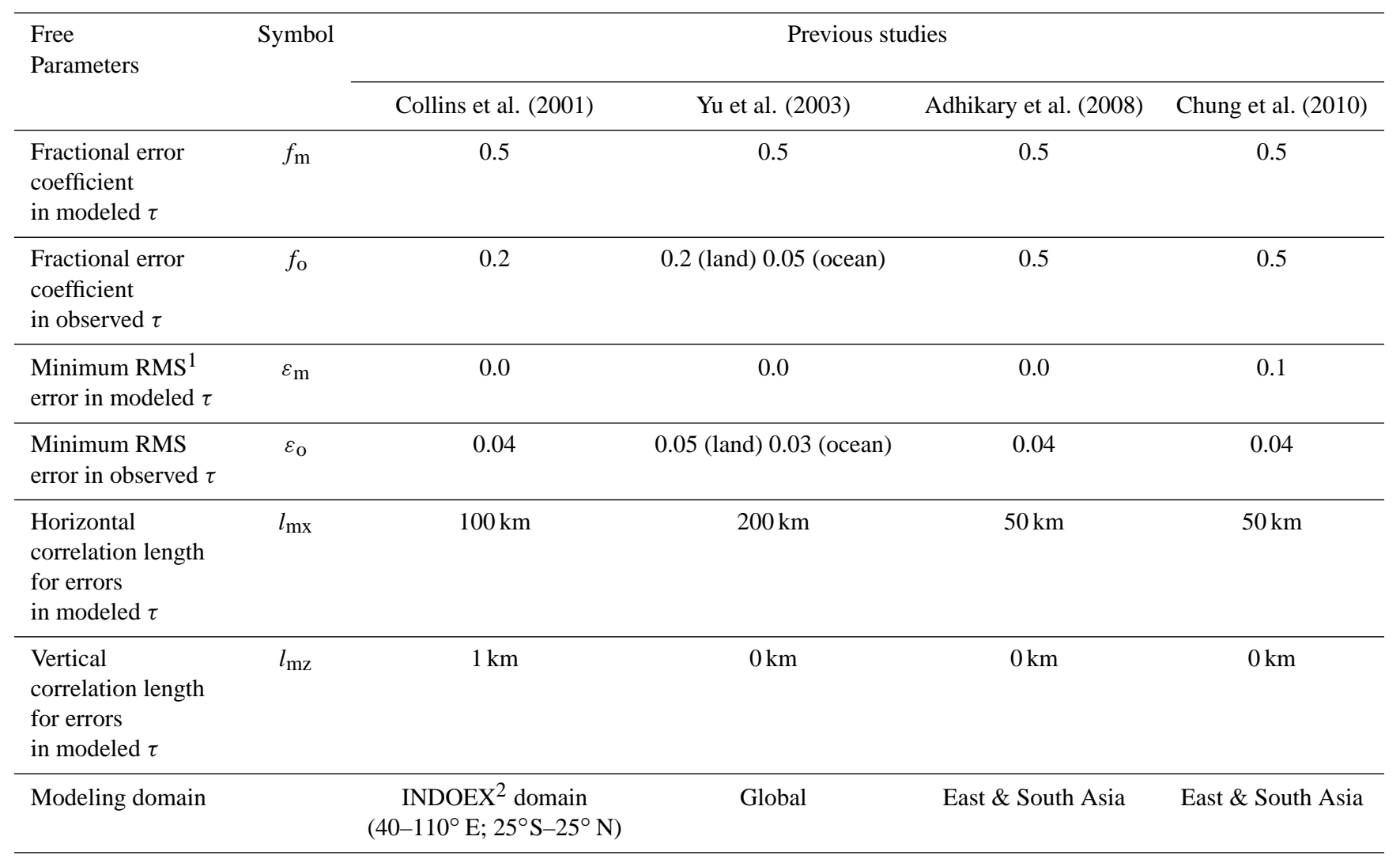

${ }^{1}$ RMS represents the Root Mean Square.

${ }^{2}$ INDOEX represents the Indian Ocean Experiment, and is a focused field experiment in the Indian Ocean, with international participation from the United States, Europe and the Indian Ocean Region.

Table 6. The best free parameters obtained from the sensitivity tests for all four seasons, 2006.

\begin{tabular}{lllll}
\hline free parameters & Spring & Summer & Fall & Winter \\
\hline$f_{\mathrm{m}}$ & 1.0 & 0.6 & 0.4 & 0.2 \\
$f_{\mathrm{o}}$ & 0.2 & 0.2 & 0.2 & 0.2 \\
$\varepsilon_{\mathrm{m}}$ & 0.0 & 0.04 & 0.0 & 0.0 \\
$\varepsilon_{\mathrm{o}}$ & 0.0 & 0.0 & 0.05 & 0.05 \\
$\chi^{2}$ between assimilated and AERONET AODs & 0.06 & 0.06 & 0.13 & 0.05 \\
& $(0.15)^{\mathrm{a}}$ & $(0.14)^{\mathrm{a}}$ & $(0.15)^{\mathrm{a}}$ & $(0.05)^{\mathrm{a}}$ \\
& $(0.07)^{\mathrm{b}}$ & $(0.07)^{\mathrm{b}}$ & $(0.14)^{\mathrm{b}}$ & $(0.06)^{\mathrm{b}}$ \\
\hline
\end{tabular}

a $\chi^{2}$ values between CMAQ-simulated and AERONET AODs.

${ }^{\mathrm{b}} \chi^{2}$ values between assimilated and AERONET AODs. In this case, for the free parameters of $f_{\mathrm{m}}, f_{\mathrm{o}}, \varepsilon_{\mathrm{m}}$, and $\varepsilon_{\mathrm{o}}, 0.8,0.2,0$ and 0.05 were used for the four seasons, respectively. 
Table 7. Statistical values between the CMAQ-simulated and MODIS-retrieved AODs for all four seasons, 2006, over East Asia.

\begin{tabular}{lcrrrrr}
\hline period & Number of data & $R$ & RMSE & MNGE & MB & MNB \\
\hline SPRING & 1178 & $\mathbf{0 . 7 7}(0.48)^{*}$ & $\mathbf{0 . 2 1}(0.33)^{*}$ & $\mathbf{3 9 . 4 2}(38.73)^{*}$ & $-\mathbf{0 . 1 5}(-0.23)^{*}$ & $-\mathbf{3 5 . 9 6}(-36.04)^{*}$ \\
SUMMER & 1311 & $\mathbf{0 . 7 3}(0.57)^{*}$ & $\mathbf{0 . 1 7}(0.28)^{*}$ & $\mathbf{4 0 . 4 1}(45.92)^{*}$ & $-\mathbf{0 . 0 6}(0.12)^{*}$ & $-\mathbf{1 7 . 5 2}(31.65)^{*}$ \\
FALL & 1274 & $\mathbf{0 . 7 9}(0.60)^{*}$ & $\mathbf{0 . 1 4}(0.39)^{*}$ & $\mathbf{3 2 . 9 0}(151.85)^{*}$ & $-\mathbf{0 . 0 4}(0.33)^{*}$ & $\mathbf{- 1 4 . 3 9}(151.31)^{*}$ \\
WINTER & 1010 & $\mathbf{0 . 6 2}(0.68)^{*}$ & $\mathbf{0 . 1 4}(0.24)^{*}$ & $\mathbf{3 4 . 6 5}(55.47)^{*}$ & $\mathbf{0 . 0 2}(0.14)^{*}$ & $\mathbf{1 3 . 8 5}(34.72)^{*}$ \\
\hline
\end{tabular}

* Statistical values between the CMAQ-simulated and MODIS-retrieved AODs during 2001-2003 (Song et al., 2008).

\section{Results and discussions}

\subsection{Evaluation of CMAQ-simulated aerosol optical properties}

In order to evaluate the accuracy of the CMAQ-simulated AODs, a comparative analysis between the CMAQsimulated and MODIS-retrieved AODs was undertaken (see Fig. 5 and Table 7). In Fig. 5, the values over land and ocean are presented with different colors and symbols, because the MODIS AOD sensor might have different sensitivity over the land and ocean and the retrieval algorithms over the land and ocean also differed. The correlation, errors and biases between the MODIS-retrieved and CMAQ-simulated AODs over the ocean (yellow triangles) were better than those over the land (blue circles). This may be due to the fact that the ocean has an almost homogeneous surface and is regarded as a dark pixel in the retrieval of aerosol optical properties.

It was found from this analysis that the accuracies of the CMAQ-simulated AODs from this study were greatly improved compared with those from the previous CMAQ modeling study conducted for the years 2001-2003 over the same modeling domain (Song et al., 2008). For example, during all four seasons, the regression coefficients $(R)$ obtained from this study (see the bold numbers in Table 7) were higher than those (see the numbers in parentheses in Table 7) from Song et al. (2008). The RMSE (absolute error), MNGE (relative error), MB (absolute bias) and MNB (relative bias) were also calculated, and then compared with those from Song et al. (2008). It was again found that the absolute/relative errors and biases were all greatly reduced compared with those from the previous study, as shown in Table 7. These better results may have been produced due to the uses of better meteorological fields, emission rates (in terms of their magnitudes and monthly variations including dust particles), an improved version of the CMAQ model, with a fine grid resolution, and the advanced algorithm for converting the 4D particulate composition to 3-D or 4-D optical properties of aerosols, as discussed in the previous sections. Particularly, the CMAQ-simulated AODs in spring were greatly improved, which may have been due to the use of the operational ADAM model in this study. Also, as reported by Bian et al. (2009), the high spatial and temporal resolutions used in the MM5-CMAQ model simulations can further enhance the
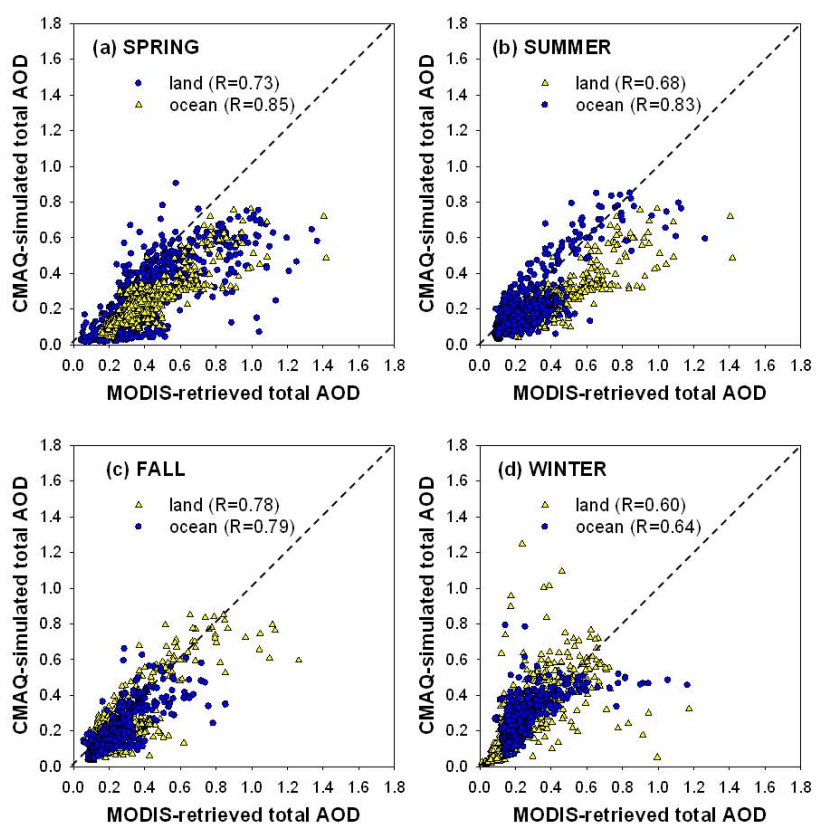

Fig. 5. Scatter plots between the CMAQ-simulated and MODISretrieved AODs for four seasons, 2006, over East Asia. Blue circles and yellow triangles indicate CMAQ-simulated AODs over ocean and land, respectively: (a) spring, (b) summer, (c) fall and (d) winter.

accuracy of the AOD products, since the relative humidity fields frequently exhibit high heterogeneities in both space and time. Obviously, in this study, both the fine spatial resolution of $30 \times 30 \mathrm{~km}^{2}$ and temporal resolution of $30 \mathrm{~s}$ were used, which may have contributed to the improved AOD products found in this study.

In addition to the AOD, the CMAQ-simulated SSAs were also compared with the AERONET SSAs at 9 AERONET sites (Fig. 6). The CMAQ-simulated SSAs show relatively good agreement with the AERONET SSAs, particularly at the Korean and Japanese sites, including the Gosan, Anmyon and Shiraham sites. However, some discrepancies were also found at the Hong_Kong_PolyU and Taipei_CWB sites during January-April. This may have been due to the fact that the BB emissions (and their plume transports) were not considered in our model simulations, which mainly occurred 


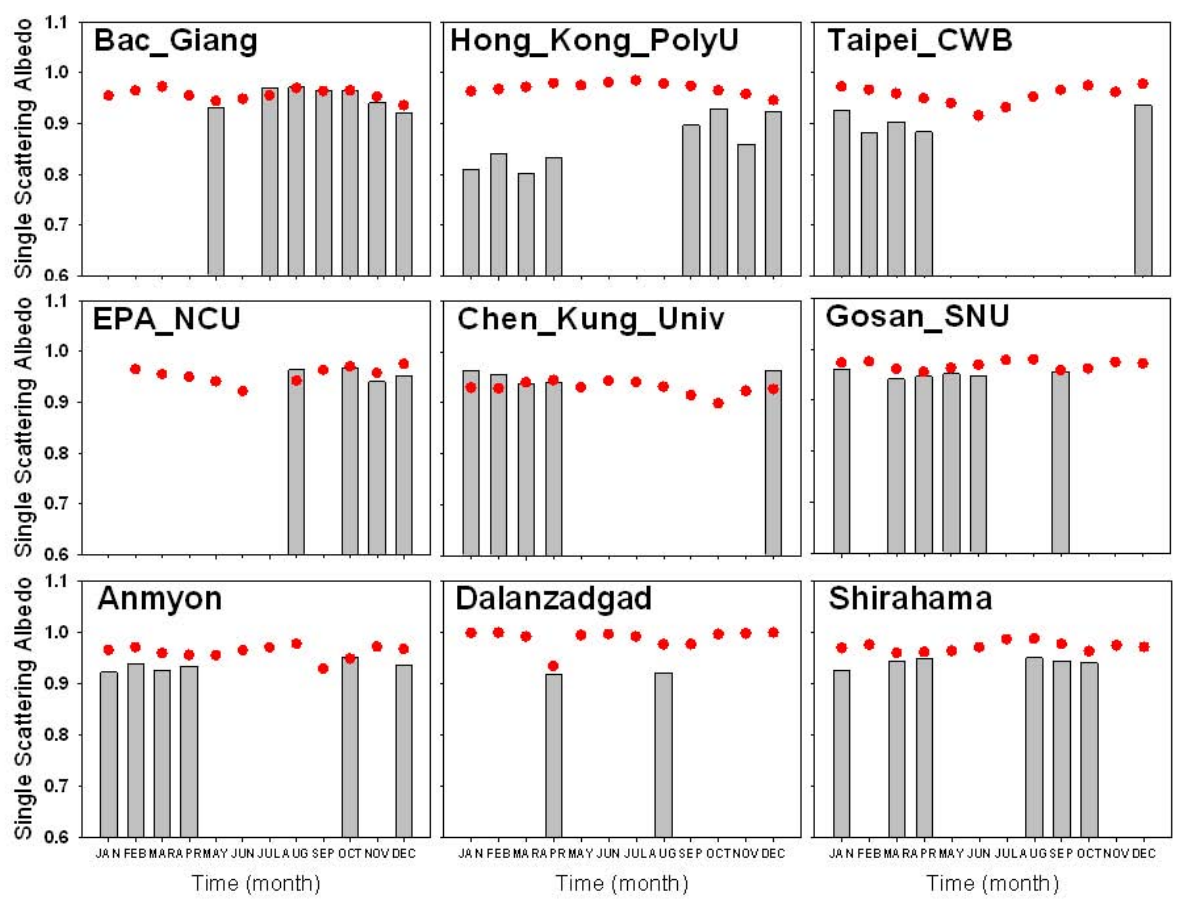

Fig. 6. Monthly variations of CMAQ-simulated and AERONET SSAs at 9 AERONET sites in East Asia for the year, 2006. Grey bars and red circles represent SSAs obtained from AERONET and CMAQ model simulations, respectively.

outside the modeling domain (i.e. Vietnam, Thailand and Myanmar). The BB plumes strongly influenced the air qualities over Hong Kong and Taiwan during spring. In particular, large amounts of BC (Black Carbon) were emitted from the $\mathrm{BB}$ activities, and such injections of $\mathrm{BC}$ from the $\mathrm{BB}$ events could have led to significant increases in the absorption of solar radiation, which subsequently made the AERONET SSAs in Fig. 6 smaller over Hong Kong and Taiwan.

There were also several uncertainties in the estimations of the extinction/absorption capability of dust particles during March-May in East Asia. This may have been due to two possible factors: (1) the uncertainty related to the amounts of dust particles predicted by the ADAM simulations and (2) the uncertainty related to the MEE of East Asian dust particles. The latter uncertainty was further related to two factors: (1) dust morphology (such as the dust particle shape and size), (2) dust mineralogy (particularly, the content of hematite, $\alpha-\mathrm{Fe}_{2} \mathrm{O}_{3}$ ) (Kaufman et al., 2002; Song et al., 2008; $\mathrm{Hu}$ and Sohki, 2009; Hansell Jr. et al., 2011). For example, the MEE values for dust particles generally decrease with increasing size of dust particles, whereas, they tend to increase when the particle shape becomes non-spherical (e.g. Hansell Jr. et al., 2011). All these factors are uncertain. As mentioned previously, in this study the size-dependent MEE values, calculated based on the data of Tegen et al. (1996), were used (instead of the MEE of $0.6 \mathrm{~m}^{2} \mathrm{~g}^{-1}$ reported originally by Malm and Hand, 2007). As shown in Fig. 6, relatively good agreements were found between AERONET SSAs and
CMAQ-calculated SSAs over the sites along the dust storm tracks such as the Dalanzadgad, Anmyon, Gosan, and Shirahama sites.

The CMAQ-simulated $\sigma_{\text {ext }}$ was also compared with the LiDAR-retrieved $\sigma_{\text {ext }}$ at six ADNET (Asia Dust NETwork) sites for all four seasons (Fig. 7). Actually, 7 ADNET sites were located in the domain, but the data from the Sapporo site were excluded, as they were too scarce. As shown in Fig. 7, the vertical profiles of the CMAQ-simulated $\sigma_{\text {ext }}$ (blue lines) were in good agreement with the LiDAR-retrieved $\sigma_{\text {ext }}$ (red circles and red bars) for all four seasons during 2006. Usually, $\sigma_{\text {ext }}$ peaked at $1 \mathrm{~km}$, and was close to zero above $3 \mathrm{~km}$, except for metropolitan regions, such as Seoul. The peak $\sigma_{\text {ext }}$ ranged between 0.5 and $1\left(10^{-4} \mathrm{~m}^{-1}\right)$ at 5 sites, except for Seoul. In Seoul, the peak $\sigma_{\text {ext }}$ increased even as high as $2.5\left(10^{-4} \mathrm{~m}^{-1}\right)$. The vertical profiles of $\sigma_{\text {ext }}$ at the Seoul site were extended to $\sim 4-5 \mathrm{~km}$.

As mentioned previously, one of the ultimate research goals is to more accurately estimate the direct radiative forcing (DRF) caused by aerosols over East Asia. In order to achieve this goal, it would have been much more desirable if the 4-D data of the optical properties of aerosols had been provided into a radiative transfer model (RTM). For the estimations of the DRF by aerosols to date, most studies have been based on column radiative modeling (CRM) (e.g. Giorgi and Qian, 2002; Park and Jeong, 2008; Ramanathan and Carmichael, 2008; Chung et al., 2010), while one of the salient features of our future works will be the inclusion of 


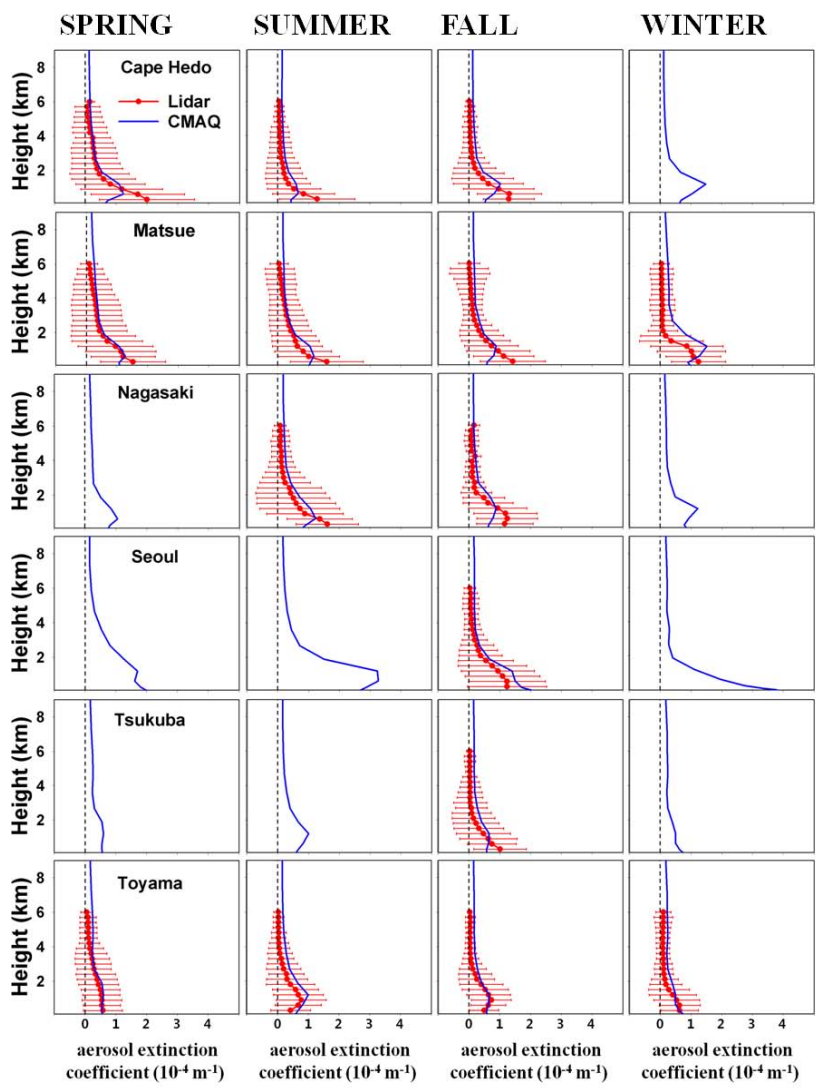

Fig. 7. Vertical profiles of the CMAQ-simulated and LIDARderived aerosol extinction coefficients $\left(\sigma_{\text {ext }}, 10^{-4} \mathrm{~m}^{-1}\right)$ from six ADNET sites in East Asia for 2006. Blue lines and red circles represent $\sigma_{\text {ext }}$ obtained from the CMAQ modeling and the LIDAR network, respectively. The horizontal red bars indicate $\pm \sigma$ (standard deviation) of the LIDAR-derived aerosol extinction coefficients. The blue dashed lines indicate the zero values of aerosol extinction coefficients.

vertically-resolved $\sigma_{\text {ext }}$ (not AOD columns) as an input to the RTM to more accurately estimate the DRF by aerosols over East Asia. In this context, Fig. 7 indicates that our CMAQmodel simulations can successfully capture the main characteristics of the vertical distributions of $\sigma_{\text {ext }}$ over East Asia and can, therefore, improve the estimations of the DRF by aerosols over East Asia. Also, the main reason for combining the CMAQ model simulations with the remote-sensing data in this study was that the remote-sensing data themselves cannot produce the complete 4-D distributions of SSAs (like Fig. 6) and the vertical distributions of $\sigma_{\text {ext }}$ (as shown in Fig. 7). These data should, therefore, be produced and provided by the CTM simulations.

\subsection{Contributions of CMAQ-simulated particulate species to total AOD}

As discussed in Eqs. (5) and (6), the CMAQ-simulated AOD is the summation of the particulate species AODs. In order to analyze the contributions of each particulate species to the AOD, the particulate species AOD $\left(\tau_{i}\right)$ for species $i$ was calculated. Firstly, the particulate species-wise aerosol extinction coefficients $\left(\sigma_{\text {ext }, i}\right)$ for 6 major particulate species (sulfate, nitrate, dust, sea salt, organic aerosols and elemental carbon) were calculated. The particulate species-wise AODs were then calculated by the integration of $\sigma_{\text {ext }, i}$ with respect to the altitude $(z)$, as follows:

$\tau_{i}=\int \sigma_{\mathrm{ext} \_i}(z) \cdot d z$

The spatial distributions of $\tau_{i}$ were analyzed for all four seasons (Fig. 8). As shown in Fig. 8, $\tau$ was dominated by $\tau_{\text {sulfate }}$ for all four seasons, with a maximum of $\tau_{\text {sulfate }}$ in summer. On the contrary, $\tau_{\text {nitrate }}$ was also dominant in winter. These phenomena have been partially discussed by Song et al. (2008). They explained that the conversion rates of $\mathrm{SO}_{2}$ to sulfate were most active in summer, due to the high temperature and intense solar radiation, which yields high levels of $\mathrm{OH}$ (hydroxyl radicals). Therefore, one would expect active $\mathrm{SO}_{2}+\mathrm{OH}$ reactions during summer. In contrast, nitrate formation is active when the temperature is low. At low temperatures, the equilibrium between the gas-phase $\mathrm{NH}_{3}, \mathrm{HNO}_{3}$ and particulate $\mathrm{NH}_{4} \mathrm{NO}_{3}$ (i.e. $\mathrm{NH}_{3}+\mathrm{HNO}_{3} \leftrightarrow \mathrm{NH}_{4} \mathrm{NO}_{3}$ ) actually shifts toward the formation of particulate $\mathrm{NH}_{4} \mathrm{NO}_{3}$. Therefore, during the cold seasons (such as winter, late fall, or spring), the formation of particulate $\mathrm{NH}_{4} \mathrm{NO}_{3}$ becomes active. As shown in Fig. 8, the contribution of $\mathrm{NH}_{4} \mathrm{NO}_{3}$ to the total AOD can increase by $\sim 23 \%$ (locally $\sim 53 \%$ ) during winter. However, in other previous studies, such as Chin et al. (2002) and Chung et al. (2010), the contribution of $\mathrm{NH}_{4} \mathrm{NO}_{3}$ to the AOD $(z)$ was ignored. It is, therefore, emphasized here that the contribution of $\mathrm{NH}_{4} \mathrm{NO}_{3}$ to $\tau$ should not be neglected, particularly during the cold seasons, in these types of studies.

$\tau_{\text {dust }}$ was high in spring when East Asian dust storms frequently erupted. The horizontal distribution of $\tau_{\text {dust }}$ showed high values over the Gobi Desert and Northeast China, because the main pathways of East Asian dust storms are from the Gobi Desert to the Korea peninsula, passing through Northeast China (again refer to Fig. 2). On the other hand, the previous version of the algorithm (Malm, 2000) did not include the sea-salt concentrations for calculating $\tau$ (Song et al., 2008). Also, the simulations via the previous version of the CMAQ v4.3 model did not include the generation and transport of sea-salt particles over the ocean surfaces (Song et al., 2008). However, this study showed that $\tau_{\text {sea-salt }}$ was not negligible over the East-China Sea and some parts of the ocean around the Japanese islands during winter. The mean contribution of sea-salt particles to $\tau$ was about $18 \%$, and 


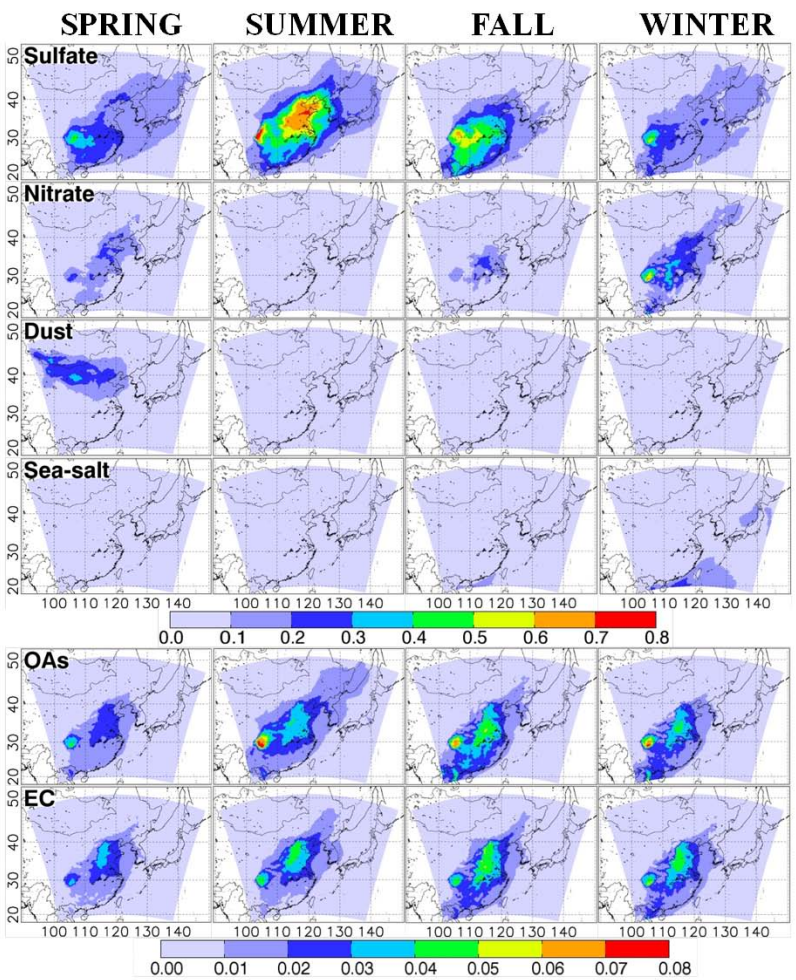

Fig. 8. Spatial distributions of the particulate species-wise AOD (i.e. $\int \sigma_{\text {ext,species }} d z$ ) for all four seasons, 2006.

the largest contribution locally increased up to $\sim 70 \%$ over the East China Sea. This means that our study was also improved by considering the sea-salt concentrations, using the new versions of the CMAQ model and algorithm (Malm and Hand, 2007).

The mass-specific $\bar{\tau}_{\mathrm{OAs}}\left(\tau_{\mathrm{OAs}} / M_{\mathrm{OAs}} ; M_{\mathrm{OAs}}\right.$ indicates the mass concentration of organic aerosols) was relatively high, but $\tau_{\mathrm{OAs}}$ was small compared with $\tau_{\text {sulfate }}$ and $\tau_{\text {nitrate }}$ for all four seasons, because $M_{\mathrm{OAs}}$ was small. The formation of organic aerosols is governed by three factors: (1) temperature, (2) the intensity of solar radiation and (3) the levels of precursors (i.e. NMVOCs). Therefore, $\tau_{\mathrm{OAs}}$ was large during summer because of high temperature and intense solar radiation, and the spatial distribution of $\tau_{\mathrm{OAs}}$ tended to follow that of the NMVOCs emissions. The contribution of organic aerosols to $\tau$ showed some discrepancies in their magnitudes and spatial distributions from the previous study (Song et al., 2008). The contribution of organic aerosols to $\tau$ in this study was smaller than that in the previous study. The high concentrations of organic aerosols during summer over South China, reported by Song et al. (2008), were not captured in this study. One of the main factors for the less active formation of organic aerosols during summer was the levels of BVOCs, such as isoprene and mono-terpenes. The CMAQ v4.5.1 model does not include the formation of organic aerosols from isoprene, but does include the secondary

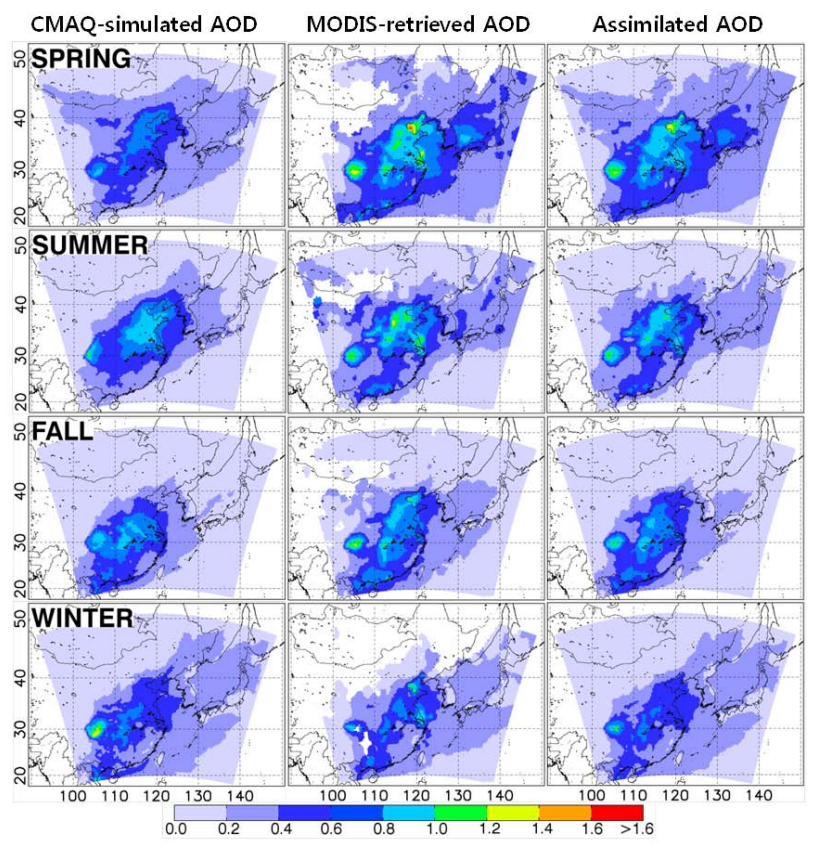

Fig. 9. Spatial distributions of the CMAQ-simulated, MODISretrieved and assimilated AODs over East Asia for all four seasons, 2006.

organic aerosol formation from mono-terpenes. The discrepancies in the organic aerosols between the two studies could have been caused by the use of different monoterpene emissions. In other words, since the "MOHYCANMEGAN" BVOC emissions were used in this study, monoterpene emission rates were on average 0.58 times smaller than the BVOC emission rates for the GEIA emission inventory used by Song et al. (2008). The mass-specific $\bar{\tau}_{\mathrm{EC}}$ was also high, but $\tau_{\mathrm{EC}}$ was small compared to $\tau_{\text {sulfate }}$ and $\tau_{\text {nitrate }}$ for all four seasons. The horizontal distributions of $\tau_{\mathrm{EC}}$ were similar to those of $\tau_{\text {sulfate }}$, but somewhat differed from those of $\tau_{\text {nitrate }}$, since the sources of elemental carbon were similar to $\mathrm{SO}_{2}$ in our model simulations.

\subsection{Comparison among CMAQ-simulated, MODIS-retrieved, assimilated, and AERONET AODs}

Figure 9 shows the spatial distributions of the CMAQsimulated, MODIS-retrieved and assimilated AODs for all four seasons of 2006. During the entire year of 2006, the AODs over Central East China (CEC; $30-40^{\circ} \mathrm{N}$ and 110 $120^{\circ} \mathrm{E}$ ) and Sichuan basin were high, because such regions include several highly-polluted urban centers, such as Beijing, Tianjin, Shanghai, Chengdu and Chongqing. It is also worth noting that near the Gobi Desert, during spring, a high AOD plume was observed due to East Asian dust storm outbreak. The high AODs over CEC were due to the high levels of particulate $\left(\mathrm{NH}_{4}\right)_{2} \mathrm{SO}_{4}$ and $\mathrm{NH}_{4} \mathrm{NO}_{3}$. This 
has already been discussed in Sect. 3.2 (also, in Fig. 8). Although the spatial distributions of the CMAQ-simulated AODs showed relatively good agreement with those of the MODIS-retrieved AODs, they were slightly underestimated compared with the MODIS-retrieved AODs (also, refer to Table 7 and Fig. 5, regarding this point). Based on the previous studies that reported the ACE-ASIA $\mathrm{NH}_{3}$ emissions may be overestimated (Kim et al., 2006; Song et al., 2008), the EDGAR emission inventory for the $\mathrm{NH}_{3}$ emissions was used in this study. The total ammonia emissions over the modeling domain from the EDGAR emission inventory were $\sim 72 \%$ of those from the ACE-ASIA emission inventory. However, an overall underestimation was found this time. The underestimation of the CMAQ-simulated AODs could have been caused partly by the use of the EDGAR $\mathrm{NH}_{3}$ emissions. Therefore, the $\mathrm{NH}_{3}$ emissions should be further verified. There is a strong need to reduce this type of uncertainty in the result, for example, from the $\mathrm{NH}_{3}$ emissions. The $\mathrm{NH}_{3}$ emission is just one example. The uncertainties can originate from many different sources, not only the $\mathrm{NH}_{3}$ emission, but also the meteorological fields, the emissions of other species, the CMAQ modeling, and the algorithm to estimate the aerosol optical properties from the aerosol composition. It is believed that the assimilation of data with observations could greatly minimize these uncertainties. In this sense, the underestimated CMAQ-simulated AODs can be partly compensated for by employing the assimilation of data with MODIS-retrieved AODs (see the third column of Fig. 9).

In Fig. 9, one more thing should also be noted: the second column of Fig. 9 shows some missing MODIS AOD values (called "bright pixels or white areas"), which were due to two main factors: (1) the areas are sun-glint areas, such as desert and snow-covered lands and, therefore, have high surface reflectance. The MODIS AOD values were not retrieved over those areas and (2) over some areas (or periods), cloud fractions were persistently high; therefore, the MODIS data were cloud-screened over these areas (or during the time periods). These "white areas" (or "white periods") can be filled spatially and temporally by conducting data assimilation (check the third column of Fig. 9), which was one of the largest advantages usually obtained when employing data assimilation.

Statistical analyses between the CMAQ-simulated, MODIS-retrieved, assimilated and AERONET AODs were conducted (Fig. 10 and Table 8), with the CMAQ-simulated, MODIS-retrieved and assimilated AODs compared to the AERONET AODs ("ground truth or reference value") via scattered plots (Fig. 10) and statistical analyses (Table 8), with $R$, RMSE, MNGE, MB and MNB. The comparisons between the CMAQ-simulated and AERONET AODs showed negative biases for all four seasons in Table 8, due to the under-prediction of the AODs via the CMAQ model simulations, as discussed before. Especially, the degrees of the negative biases were high ( $R$ values were also small) in spring and summer compared with the statistical values
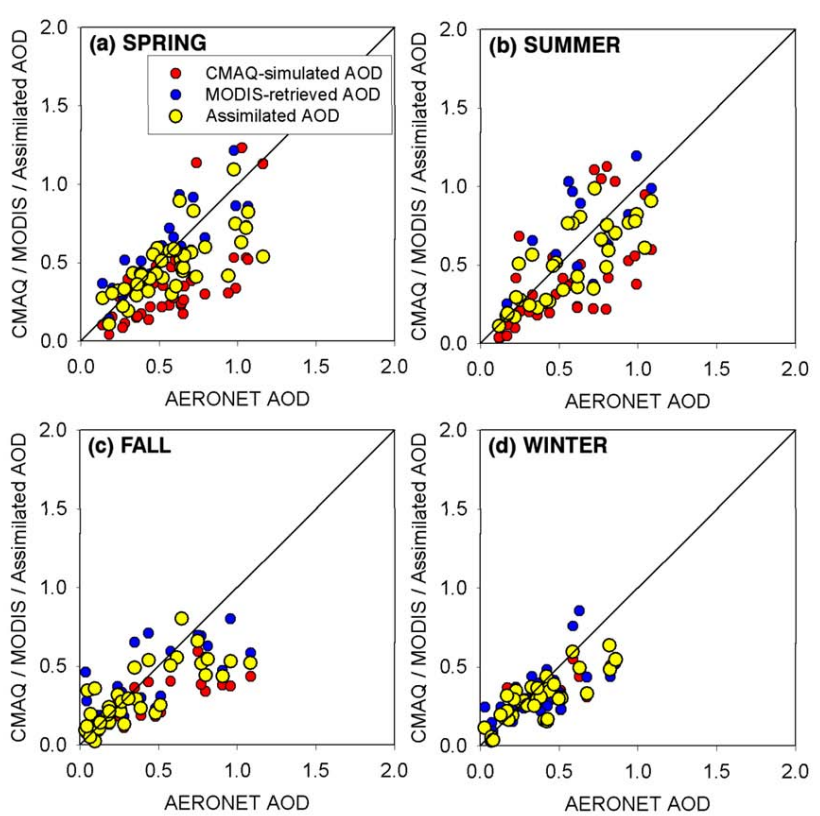

Fig. 10. Scatter plots of the CMAQ-simulated, MODIS-retrieved, assimilated and AERONET AODs for all four seasons, 2006. Red, blue and yellow circles indicate CMAQ-simulated, MODISretrieved and assimilated AODs, respectively: (a) spring, (b) summer, (c) fall and (d) winter.

for the other seasons. As mentioned previously, there were strong BB activities during January-April, but our CMAQ model simulations did not consider the $\mathrm{BB}$ emissions and subsequent BB plume transports over East Asia. The highly negative biases during spring and summer could have been caused partly to the biomass burning activities not being considered in our model simulations. According to the statistical values shown in Table 8, the AODs were improved after the data assimilation, although they were still underestimated (i.e. negative biases) (note in Table 8 the increases in the $R$ values and the decreases in the errors and the biases after the data assimilation). Particularly, the AODs were greatly improved in spring and summer, but not in winter, after the data assimilation, because the CMAQ-simulated AODs were closer to the AERONET AODs than the MODIS-retrieved AODs in winter.

\subsection{Monthly and daily variations of AODs}

In this section, the monthly and daily variations of AODs were further analyzed at several AERONET sites. These analyses were conducted from two perspectives, i.e. the "monthly variation" in the optical properties of aerosols could be meaningful in term of radiative forcing by aerosol; whereas, the "daily variations" could be more meaningful in the investigations of particulate pollution.

First of all, the monthly variations of CMAQ-simulated, MODIS-retrieved, assimilated, and AERONET AODs were 
Table 8. Statistical values between the CMAQ-simulated, MODIS-retrieved, assimilated and AERONET AODs for all four seasons, 2006.

\begin{tabular}{llcrrrrr}
\hline AERONET vs. & period & Number of data & $R$ & RMSE & MNGE & MB & MNB \\
\hline CMAQ & SPRING & 41 & 0.59 & 0.31 & 45.24 & -0.19 & -29.88 \\
& SUMMER & 33 & 0.61 & 0.30 & 48.47 & -0.13 & -22.45 \\
& FALL & 37 & 0.69 & 0.24 & 61.08 & -0.10 & 11.84 \\
& WINTER & 38 & 0.79 & 0.15 & 34.86 & -0.07 & -4.78 \\
\hline \multirow{2}{*}{ MODIS } & SPRING & 41 & 0.65 & 0.21 & 30.18 & -0.05 & 1.76 \\
& SUMMER & 33 & 0.75 & 0.20 & 31.43 & -0.01 & 3.98 \\
& FALL & 36 & 0.75 & 0.20 & 108.36 & 0.01 & 87.81 \\
& WINTER & 38 & 0.72 & 0.15 & 49.37 & -0.04 & 17.12 \\
\hline \multirow{2}{*}{ Assimilated } & SPRING & 41 & 0.71 & 0.20 & 26.41 & -0.09 & -8.69 \\
& SUMMER & 33 & 0.79 & 0.19 & 28.10 & -0.06 & -5.02 \\
& FALL & 36 & 0.77 & 0.20 & 63.15 & -0.06 & 26.05 \\
& WINTER & 38 & 0.80 & 0.15 & 35.81 & -0.07 & -4.77 \\
\hline
\end{tabular}

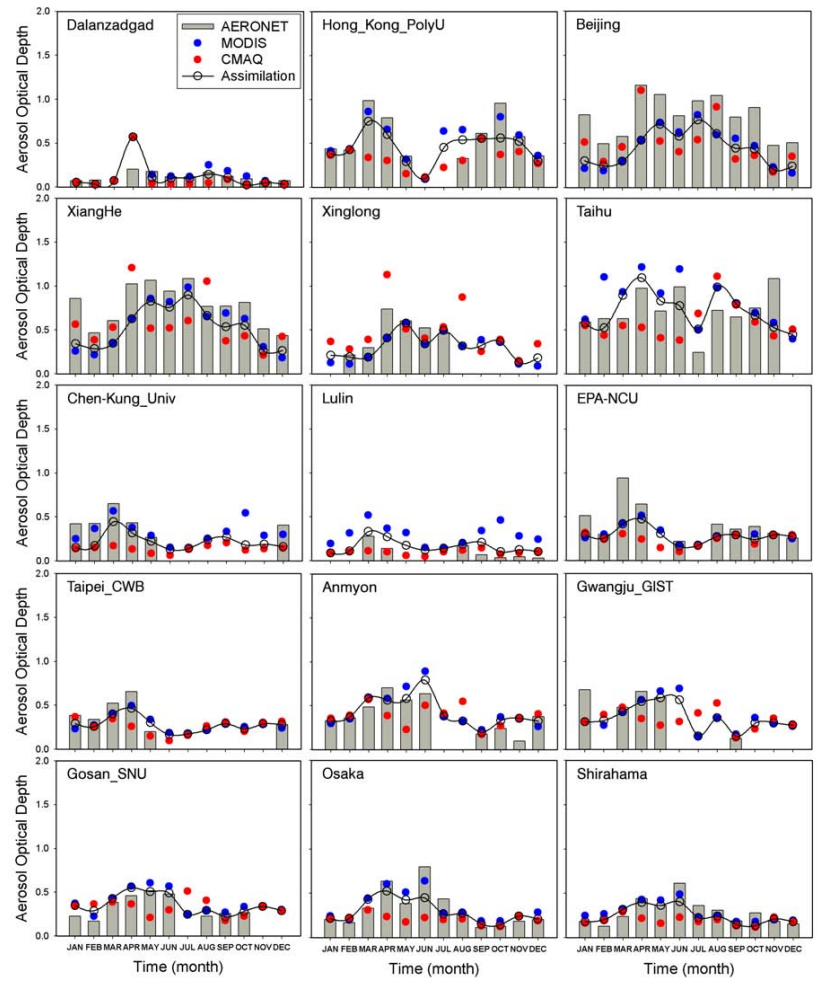

Fig. 11. Monthly variations in the MODIS-retrieved, CMAQsimulated, assimilated and AERONET AODs at 15 AERONET sites over East Asia for 2006. Grey bars, blue circles, red circles and black solid lines represent AODs obtained from AERONET, MODIS, CMAQ and assimilation, respectively.

analyzed at the 15 AERONET sites shown in Fig. 11. There appears to be two things of note in Fig. 11. As mentioned before, the CMAQ-simulated AODs (red dots) were generally smaller than the AERONET AODs (grey bars). These underestimations were significantly corrected after the assimilation of data with the MODIS-retrieved AODs (black solid lines with open circles). Secondly, the CAPSS and REAS emission inventories were believed to be more accurate than the INTEX-B emission inventory (personal communication with Dr. T. Ohara at NIES (National Institute for Environmental Studies) in Japan; also refer to Han et al., 2011a and Lee et al., 2011). Therefore, the uses of the CAPSS and REAS emission inventories led to relatively better agreements between the observed and modeled AOD values at the Korean and Japanese sites, including Anmyon, Gwangju_GIST, Gosan_SNU, Osaka, and Shirahama. Overall, after the data assimilation with the MODIS-retrieved AODs, the monthly-averaged assimilated AODs agreed well with those of the AERONET AODs. In addition, Fig. 11 clearly shows a major benefit from using data assimilation: the assimilation was able to provide AOD values, even when the MODIS-retrieved and/or AERONET AODs were not available.

On the other hand, as mentioned in Sect. 1, the AOD can be regarded as a proxy of $\mathrm{PM}_{2.5}$ and/or $\mathrm{PM}_{10}$ within the boundary layer (BL), and the relationship between the AOD and PM concentration is sensitive to the BL height and the vertical profiles of aerosols within BL (e.g. Gupta et al., 2006; Schaap et al., 2009). From this perspective, the "dailyaveraged" AOD could be an important factor for analyzing and forecasting particulate air pollution over East Asia. The daily variations in the CMAQ-simulated, MODIS-retrieved, assimilated and AERONET AODs were also compared at 3 AERONET sites (EPA_NCU, Gosan_SNU, and Osaka sites), as shown in Fig. 12. In Fig. 12, one month per season was selected, depending on the AERONET data availability. The comparisons between the assimilated and AERONET AODs matched one another to some degree. However, it was also obvious that the assimilated AODs did not capture several peaks (high PM episodes) of the AERONET AODs. 


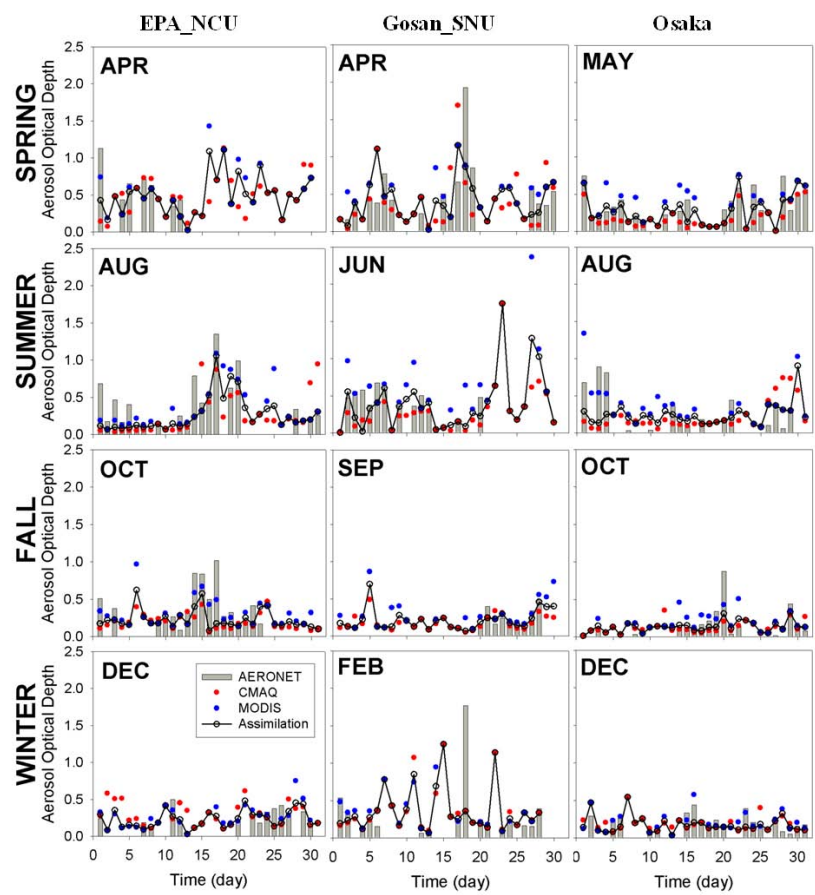

Fig. 12. Daily variations in the MODIS-retrieved, CMAQsimulated, assimilated and AERONET AODs at the 3 AERONET sites in East Asia for all four seasons, 2006. Grey bars, blue circles, red circles and black solid lines represent AODs obtained from AERONET, MODIS, CMAQ and assimilation, respectively.

Although there were some degrees of agreements between the assimilated/modeled and AERONET AODs, further improvements in the CMAQ model simulations should definitely be made for use of the CMAQ model simulations in air pollution studies and/or the development of a particulate forecasting system over East Asia.

\section{Summary and conclusions}

In this study, the accuracy of the CMAQ-derived AODs was improved in several ways: (1) the wind fields from MM5 simulations were assimilated with the QuikSCAT wind data; (2) the emission inventories of INTEX-B (for China and North Korea), REAS (for Japan) and CAPSS (for South Korea) were used for the 2006 simulations; (3) for the $\mathrm{NH}_{3}$ and BVOC emissions, the EDGAR and "MOHYCAN-MEGAN" emissions, respectively, were used; (4) the monthly variations in the $\mathrm{NO}_{\mathrm{x}}, \mathrm{NH}_{3}, \mathrm{NMVOCs}$ and $\mathrm{SO}_{2}$ emissions were also applied; (5) to consider dust generation and transport in the domain, the operational ADAM at the KMA was used; (6) all the MET/CMAQ model simulations and emissions (modeling) were conducted using a fine grid resolution of $30 \times 30 \mathrm{~km}^{2}$ for the entire year of 2006 ; (7) the 4-D particulate species concentrations obtained from the CMAQ model simulations were converted into the 3-D or
4-D aerosol optical products, using the Malm and Hand (2007) algorithm with further modifications; and finally (8) the CMAQ-simulated AOD products were assimilated with the MODIS-retrieved AOD, using the optimal interpolation technique. These improvements were evaluated by comparing the CMAQ-simulated and MODIS-retrieved AODs. The qualities of the CMAQ-simulated SSAs and $\sigma_{\text {ext }}$ were also assessed with the AERONET SSAs and LiDAR-retrieved $\sigma_{\text {ext }}$. In general, relatively good agreements were achieved between the vertical profiles of the CMAQ-simulated $\sigma_{\text {ext }}$ and LiDAR-retrieved $\sigma_{\text {ext }}$, indicating that our CMAQ-model simulations were able to capture the main characteristics of the vertical distributions of $\sigma_{\text {ext }}$ in East Asia. In future, the vertically-resolved $\sigma_{\text {ext }}$ will be input to a RTM to better estimate the DRF by aerosols in East Asia.

Meanwhile, the contributions of the particulate specieswise AOD to total AOD $(\tau)$ were also investigated. The CMAQ-simulated AODs were mainly contributed by sulfate throughout the year, with the exception of winter. During winter, $\mathrm{NH}_{4} \mathrm{NO}_{3}$ was the dominant contributor to $\tau$. In particular, this large contribution of $\mathrm{NH}_{4} \mathrm{NO}_{3}$ to $\tau$ during winter has been neglected in several previous studies (e.g. Chin et al., 2002; Chung et al., 2010), but this contribution should be taken into account. It was also found that the dust and sea-salt particles were important species in $\tau$ during spring and winter, respectively. Also, the contribution of organic aerosols (OAs) to $\tau$ became smaller than that found in the previous study (Song et al., 2008). These differences could have been caused by the use of the reduced mono-terpene emissions in this study.

Although our CMAQ model simulations were improved in several ways, and the CMAQ-simulated aerosol optical properties showed relatively good accuracy, the use of the data assimilation technique could provide further improvements in the qualities of the optical properties of aerosols over East Asia. Through the data assimilation, the accuracies of the monthly and daily averaged AODs were also greatly improved compared with those of the AERONET AODs. In the future, based on the accurate monthly and daily AODs, the direct radiative forcing by aerosols, and the spatial distributions of $\mathrm{PM}_{2.5}$ or $\mathrm{PM}_{10}$ at the surface, will be able to be estimated more accurately.

\section{Appendix A}

In this study, several statistical parameters were introduced for comparing the CMAQ-simulated, MODIS-retrieved, assimilated and AERONET AODs: 
Regression coefficient $(R)=$

$$
\frac{N \sum_{1}^{N} \tau_{i, \mathrm{M}} \tau_{i, \mathrm{O}}-\sum_{1}^{N} \tau_{i, \mathrm{M}} \sum_{1}^{N} \tau_{i, \mathrm{O}}}{\sqrt{N \sum_{1}^{N} \tau_{i, \mathrm{M}}^{2}-\left(\sum_{1}^{N} \tau_{i, \mathrm{M}}\right)^{2}} \sqrt{N \sum_{1}^{N} \tau_{i, \mathrm{O}}^{2}-\left(\sum_{1}^{N} \tau_{i, \mathrm{O}}\right)^{2}}}
$$

Root mean square error $(\mathrm{RMSE})=$

$$
\sqrt{\frac{1}{N} \sum_{1}^{N}\left(\tau_{i, \mathrm{M}}-\tau_{i, \mathrm{O}}\right)^{2}}
$$

Mean normalized gross error $(\mathrm{MNGE})=$

$\frac{1}{N} \sum_{1}^{N}\left(\frac{\left|\tau_{i, \mathrm{M}}-\tau_{i, \mathrm{O}}\right|}{\tau_{i, \mathrm{O}}}\right) \times 100$

Mean bias $(\mathrm{MB})=$

$\frac{1}{N} \sum_{1}^{N}\left(\tau_{i, \mathrm{M}}-\tau_{i, \mathrm{O}}\right)$

Mean Normalized bias $(\mathrm{MNB})=$

$\frac{1}{N} \sum_{1}^{N}\left(\frac{\tau_{i, \mathrm{M}}-\tau_{i, \mathrm{O}}}{\tau_{i, \mathrm{O}}}\right) \times 100$

where $N$ is the number of data and $\tau_{i, \mathrm{M}}$ and $\tau_{i, \mathrm{O}}$ the CMAQ-simulated AODs and MODIS-retrieved, assimilated or AERONET AODs, respectively. $R$ measures the degree to which two variables are linearly correlated, and ranges between -1 and 1 . RMSE and MNGE were used to interpret how well the model results explain a given set of observations. MB and MNB were used to explain the degree to which the model results were over- or under-estimated compared with the observations. Positive (negative) MB and MNB indicate an overestimation (underestimation) via the model simulations.

\section{Supplementary material related to this article is available online at: http://www.atmos-chem-phys.net/11/12275/2011/ acp-11-12275-2011-supplement.pdf.}

Acknowledgements. This work was funded by the Mid-Career Research Program through the National Research Foundation from the Korean Ministry of Education, Science and Technology (MEST) under grant 2010-0014058 and the Korean Meteorological Administration Research and Development Program under grant RACS 2010-2010. The REAS emissions for the year of 2006 were downloaded from http://www.jamstec.go.jp/frcgc/research/p3/reas_h_b.html. The LiDAR-retrieved aerosol extinction coefficient data were obtained from the ADNET (Asian Dust Network), which has been managed by NIES (National Institute for Environmental Studies) in Japan (http://www-lidar.nies.go.jp).

Edited by: A. Richter

\section{References}

Adhikary, B., Kulkarni, S., Dallura, A., Tang, Y., Chai, T., Leung, L. R., Qian, Y., Chung, C. E., Ramanathan, V., and Carmichael, G. R.: A regional scale chemical transport modeling of Asian aerosols with data assimilation of AOD observations using optimal interpolation technique, Atmos. Environ., 42, 8600-8615, 2008.

Bian, H., Chin, M., Rodriguez, J. M., Yu, H., Penner, J. E., and Strahan, S.: Sensitivity of aerosol optical thickness and aerosol direct radiative effect to relative humidity, Atmos. Chem. Phys., 9, 2375-2386, doi:10.5194/acp-9-2375-2009, 2009.

Byun, D. W. and Ching, J. K. S.: Science algorithms of the EPA models-3 Community Multiscale Air Quality (CMAQ) modeling system, EPA/600/R-99/030, US EPA, Research Triangle Park, USA, 1999.

Byun, D. W. and Schere, K. L.: Review of the governing equations, computational algorithm, and other components of the Models-3 Community Multi-scale Air Quality (CMAQ) Modeling system, Appl. Mech. Rev., 59, 51-77, 2006.

Charlson, R. J., Langner, J., Rodhe, H., Leovy, C. B., and Warren, S. G.: Perturbation of the Northern Hemisphere radiative balance by black scattering from anthropogenic sulfate aerosols, Tellus A., 43, 152-163, 1991.

Chin, M., Ginoux, P., Kinne, S., Torres, O., Holben, B. N., Duncan, B. N., Martin, R. V., Logan, J. A., Higurashi, A., and Nakajima, T.: Tropospheric aerosol optical thickness from the GOCART model and comparisons with satellite and sunphotometer measurements, J. Atmos. Sci., 59, 461-483, 2002.

Chin, M., Chu, A., Levy, R., Remer, L., Kaufman, Y., Holben, B., Eck, T., Ginoux, P., and Gao, Q.: Aerosol distribution in the Northern Hemisphere during ACE-Asia: Results from global model, satellite observations, and sunphotometer measurements, J. Geophys. Res.,109, D23S90, doi:10.1029/2004JD004829, 2004.

Chung, C. E., Ramanathan, V., Carmichael, G., Kulkarni, S., Tang, Y., Adhikary, B., Leung, L. R., and Qian, Y.: Anthropogenic aerosol radiative forcing in Asia derived from regional models with atmospheric and aerosol data assimilation, Atmos. Chem. Phys., 10, 6007-6024, doi:10.5194/acp-10-6007-2010, 2010.

Coakley, J. A. and Cess, R. D.: Response of the NCAR Community Climate Model to the radiative forcing by the naturally-occurring tropospheric aerosol, J. Atmos. Sci., 42, 1677-1692, 1985.

Collins, W. D., Rasch, P. J., Eaton, B. E., Khattatov, B. V., and Lamarque, J.-F.: Simulating aerosols using a chemical transport model with assimilation of satellite aerosol retrievals: Methodology for INDOEX, J. Geophys. Res., 106, 7313-7336, 2001.

Conant, W. C., Seinfeld, J. H., Wang, J., Carmichael, G. R., Tang, Y., Uno, I., Flatau, P. J., Markowicz, K. M., and Quinn, P. K.: A model for the radiative forcing during ACE-Asia derived from CIRPAS Twin Ottor and R/V Ronald H. Brown data and omposition with observations, J. Geophys. Res., 108, 8661, doi:10.1029/2002JD003206, 2003. 
Curier, R. L., Veefkind, J. P., Braak, R., Veihelmann, B., Torres, O., and de Leeuw, G.: Retrieval of aerosol optical properties from OMI radiances using a multiwavelength algorithm Application to western Europe, J. Geophys. Res., 113, D17S90, doi:10.1029/2007JD008738, 2008.

Donlon, C. J., Nightingale, T. J., Sheasby, T., Turner, J., Robinson, I. S., and Emery, W. J.: Implications of the oceanic thermal skin temperature deviation at high wind speed, Geophys. Res. Lett., 26, 2505-2508, 1999.

Giorgi, F., Bi, X., and Qian, Y.: Direct radiative forcing and regional climatic effects of anthropogenic aerosols over East Asia: A regional coupled climate-chemistry/aerosol model study, J. Geophys. Res., 107, 4439, doi:10.1029/2001JD001066, 2002.

Grell, G. A., Dudhia, J., and Stauffer, D. R.: A description of the fifth-generation Penn State/NCAR mesoscale model (MM5), NCAR Technical Note, NCAR/TN-398+STR, 117, 1994.

Gupta, P., Christopher, S. A., Wang, J., Gehrig, R., Lee, and Y., Kumar, N.: Satellite remote sensing of particulate matter and air quality assessment over global cities, Atmos. Environ., 40, 5880-5892, 2006.

Han, K. M., Song, C. H., Ahn, H. J., Park, R. S., Woo, J. H., Lee, C. K., Richter, A., Burrows, J. P., Kim, J. Y., and Hong, J. $\mathrm{H}$.: Investigation of $\mathrm{NO}_{\mathrm{x}}$ emissions and $\mathrm{NO}_{\mathrm{x}}$-related chemistry in East Asia using CMAQ-predicted and GOME-derived $\mathrm{NO}_{2}$ columns, Atmos. Chem. Phys., 9, 1017-1036, doi:10.5194/acp9-1017-2009, 2009.

Han, K. M, Lee, C. K., Lee, J. H., Kim, J., and Song, C. H.: A comparison study between model-predicted and OMI-retrieved tropospheric $\mathrm{NO}_{2}$ columns over the Korean peninsula, Atmos. Environ., 45, 2962-2971, 2011a.

Hansell Jr., R. A., Reid, J. S., Tsay, S. C., Roush, T. L., and Kalashnikova, O. V.: A sensitivity study on the effects of particle chemistry, asphericity and size on the mass extinction efficiency of mineral dust in the earth's atmosphere: from the near to thermal IR, Atmos. Chem. Phys., 11, 1527-1547, doi:10.5194/acp-111527-2011, 2011.

Holben, B. N., Tanre, D., Smirnov, A., Eck, T. F., Slutsker, I., Abuhassan, N., Newcomb, W. W., Schafer, J. S., Chatenet, B., Lavenu, F., Kaufman, Y. J., Vande Castle, J., Setzer, A., Markham, B., Clark, D., Frouin, R., Halthore, R., Karneli, A., O'Neill, N. T., Pietras, C., Pinker, R. T., Voss, K., and Zibordi, G.: An emerging ground-based aerosol climatology: Aerosol optical depth from AERONET, J. Geophys. Res., 106, 1206712097, 2001.

Hong, S.-Y. and Pan, H.-L.: Nonlocal boundary layer vertical diffusion in a medium-range forecast model, Mon. Weather Rev., 124, 2322-2339, 1996.

$\mathrm{Hu}$, R.-M. and Sokhi, R. S.: Light scattering and absorption properties of dust particles retrieved from satellite measurements, J. Quant. Spectroc. Ra., 110, 1698-1705, 2009.

Hwang, H. and Ro, C.-U.: Single-particle characterization of four aerosol samples collected in ChunCheon, Korea, during Asian dust storm events in 2002, J. Geophys. Res., 110, D23201, doi:10.1029/2005JD006050, 2005.

In, H.-J. and Park, S.-U.: The soil particle size dependent emission parameterization for an Asian dust (Yellow Sand) observed in Korea on April 2002, Atmos. Environ., 37, 4625-4636, 2003.

Kacenelenbogen, M., Léon, J.-F., Chiapello, I., and Tanré, D.: Characterization of aerosol pollution events in France using ground- based and POLDER-2 satellite data, Atmos. Chem. Phys., 6, 4843-4849, doi:10.5194/acp-6-4843-2006, 2006.

Kaufman, Y. J., Tanre, D., and Boucher, O.: A satellite view of aerosols in the climate system, Nature, 419, 215-223, 2002.

Kim, J. Y., Song, C. H., Ghim, Y. S., Won, J. G., Yoon, S.-C., Carmichael, G. R., and Woo, J. H.: An investigation on $\mathrm{NH}_{3}$ emissions and particulate $\mathrm{NH}_{4}^{+}$and $\mathrm{NO}_{3}^{-}$formation in East Asia, Atmos. Environ., 40, 2139-2150, 2006.

Kim, S. B., Yumimoto, K., Uno, I., and Chun, Y.: Dust model intercomparison between ADAM and CFORS/Dust for Asian dust case in 2007 (March 28-April 3), SOLA, 7A, 025-028, 2011.

King, M. D., Kaufman, Y. J., Tanre, D., and Nakajima, T.: Remote sensing of tropospheric aerosols from space: Past, present, and future, B. Am. Meteorol. Soc., 80, 2229-2259, 1999.

Kinne, S., Lohmann, U., Feichter, J., Schulz, M., Timmreck, C., Ghan, S., Easter, R., Chin, M., Ginoux, P., Takemura, T., Tegen, I., Koch, D., Herzog, M., Penner, J., Pitari, G., Holben, B., Eck, T., Smirnov, A., Dubovik, O., Slutsker, I., Tanre, D., Torres, O., Mishchenko, M., Geogdzhayev, I., Chu, D. A., and Kaufman, Y.: Monthly averages of aerosol properties: A global comparison among models, satellite data, and AERONET ground data, J. Geophys. Res., 108, 4634, doi:10.1029/2001JD001253, 2003.

Kokhanovsky, A. A., von Hoyningen-Huene, W., and Burrow, J. P.: Atmospheric aerosol load from space, Atmos. Res., 81, 176-185, 2006.

Lee, S. J., Han, K. M., Park, M. E., Park, R. S., and Song, C. H.: Estimation of the accuracy of $\mathrm{NO}_{\mathrm{x}}$ emissions over Japan via comparisons between CMAQ-simulated and OMI-retrieved tropospheric $\mathrm{NO}_{2}$ columns, in preparation, 2011.

Levy, R. C., Remer, L. A., Mattoo, S., Vermote, E. F., and Kaufman, Y. J.: A second-generation operational algorithm: Retrieval of aerosol properties over land from inversion of MODIS reflectance, J. Geophys. Res., 112, D13211, doi:10.1029/2006JD007811, 2007.

Livingston, J. M., Redemann, J., Russell, P. B., Torres, O., Veihelmann, B., Veefkind, P., Braak, R., Smirnov, A., Remer, L., Bergstrom, R. W., Coddington, O., Schmidt, K. S., Pilewskie, P., Johnson, R., and Zhang, Q.: Comparison of aerosol optical depths from the Ozone Monitoring Instrument (OMI) on Aura with results from airborne sunphotometry, other space and ground measurements during MILAGRO/INTEX-B, Atmos. Chem. Phys., 9, 6743-6765, doi:10.5194/acp-9-6743-2009, 2009.

Malm, W. C., Sisler, J. F., Huffman, D., Eldred, R. A., and Cahill, T. A.: Spatial and seasonal trends in particle concentration and optical extinction in the United States, J. Geophys. Res., 99, 13471370, 1994.

Malm, W. C.: Spatial and seasonal patterns and temporal variability of haze and its constituents in the United States: Report III (Chapter 3), US EPA, 1-38, 2000.

Malm, W. C. and Hand, J. L.: An examination of the physical and optical properties of aerosols collected in the IMPROVE program, Atmos. Environ., 41, 3407-3427, 2007.

Maxwell-Meier, K., Weber, R. J., Song, C. H., Orsini, D., Ma, Y., Carmichael, G. R., Streets, D. G., and Blomquist, B.: Inorganic composition of particles in mixed mineral dust-pollution plumes observed from airborne measurements during ACE-Asia, J. Geophys. Res., 109, D19S07, doi:10.1029/2003JD004464, 2004.

Minobe, S., Akira, K.-Y., Komori, N., Xie, S.-P., and Small, R. J.: 
Influence of the Gulf Stream on the troposphere, Nature, 452, 206-209, 2008.

Noh, Y. M., Müller, D., Shin, D.H., and Lee, K. H.: Retrieval of lidar overlap factor using raman lidar system, J. Korean Soc. Atmos. Environ., 25, 450-458, 2009.

Paciorek, C. J., Liu, Y., Monreno-Macias, H., and Kondragunta, S.: Spatiotemporal associations between GOES aerosol optical depth retrievals and ground-level $\mathrm{PM}_{2.5}$, Environ. Sci. Technol., 42, 5800-5806, 2008.

Park, K.-A., Sakaida, F., and Kawamura, H.: Error characteristics of satellite-observed sea surface temperatures in the northeast Asian sea, J. Korean Earth Sci. Soc., 29, 280-289, 2008.

Park, R. S., Cho, Y.-K., Choi, B.-J., and Song, C. H.: Implications of sea surface temperature deviations in the prediction of wind and precipitable water over the Yellow Sea, J. Geophys. Res.,116, D17106, doi:10.1029/2011JD016191, 2011.

Park, S.-U. and In, H.: Parameterization of dust emission for the simulation of the yellow sand (Asian dust) event observed in March 2002 in Korea, J. Geophys. Res., 108, 4618, doi:10.1029/2003JD003484, 2003.

Park, S.-U. and Lee, E.-H.: Parameterization of Asian dust (Hwangsa) particle-size distributions for use in dust emission models, Atmos. Environ., 38, 2155-2162, 2004.

Park, S.-U. and Jeong, J. I.: Direct radiative forcing due to aerosols in Asia during March 2002, Sci. Total Environ., 407, 394-404, 2008.

Ramanathan, V., Ramana, M. V., Roberts, G., Kim, D., Corrigan, C., Chung, C., and Winker, D.: Warming trend in Asia amplified by brown cloud solar absorption, Nature Geosci., 448, 575-579, doi:10.1038/nature06019, 2007.

Ramanathan, V. and Carmichael, G.: Global and regional climate changes due to black carbon, Nature Geosci., 1, 221-227, 2008.

Reisner, J., Rasmussen, R. J., and Bruintjes, R. T.: Explicit forecasting of supercooled liquid water in winter storms using MM5 mesoscale model, Q. J. Roy. Meteor. Soc., 124B, 1071-1107, 1998.

Remer, L. A., Kaufman, Y. J., Tanre, D., Mattoo, S., Chu, D. A., Martins, J. V., Li, R-R., Ichoku, C., Levy, R. C., Kleidman, R. G., Eck, T. F., Vermote, E., and Holben, B. N.: The MODIS Aerosol Algorithm, Products and Validation, J. Atmos. Sci., 62, 947-973, 2005.

Ro, C.-U., Hwang, H., Kim, H., Chun, Y.S., and van Grieken, R.: Single particle characterization of four "Asian dust" samples collected in Korea, using low-Z particle electron probe X-ray microanalysis, Environ. Sci. Technol., 39, 1409-1419, 2005.

Rosenfeld, D.: Suppression of rain and snow by urban and industrial air pollution, Science, 287, 1793-1796, 2000.

Shao, Y., Yang, Y., Wang, J., Song, Z., Leslie, L., M., Dong, C., Zhang, Z., Lin, Z., Kanai, Y., Yabuki, S., and Chun, Y.: Northeast Asian dust storms: Real-time numerical prediction and validation, J. Geophys. Res., 108, 4691, doi:10.1029/2003JD003667, 2003.

Shimizu, A., Sugimoto, N., Matsui, I., Arao, K., Uno. I., Murayama, T., Kagawa, N., Aoki, K., Uchiyama, A., and Yamazaki, A.: Continuous observations of Asian dust and other aerosols by polarization lidars in China and Japan during ACE-Asia, J. Geophys. Res., 109, D19S17, doi:10.1029/2002JD003253, 2004.

Shimizu, A., Sugimoto, N., and Matsui I.: Detailed description of data processing system for LiDAR network in East Asia, 25th
International Laser Radar Conference, 911-913, 2010.

Shimizu, A., Sugimoto, N., Matsui I., Mori, I., Nishikawa, M., and Kido, M.: Relationship between LiDAR-derived dust extinction coefficients and mass concentrations in Japan, SOLA, 7A, 001004, 2011.

Singh, H. B. and Jacob, D. J.: Future Directions: Satellite observations of tropospheric chemistry, Atmos. Environ., 34, 43994401, 2000.

Schaap, M., Apituley, A., Timmermans, R. M. A., Koelemeijer, R. B. A., and de Leeuw, G.: Exploring the relation between aerosol optical depth and $\mathrm{PM}_{2.5}$ at Cabauw, the Netherlands, Atmos. Chem. Phys., 9, 909-925, doi:10.5194/acp-9-909-2009, 2009.

Song, C. H., Maxwell-Meier, K., Weber, R. J., Kapustin, V., and Clarke, A.: Dust composition and mixing state inferred from airborne composition measurements during ACE-Asia C130 Flight\#6, Atmos. Environ., 39, 359-369, 2005.

Song, C. H., Kim, C. M., Lee, Y. J., Carmichael, G. R., Lee, B. K., and Lee, D. S.: An evaluation of reaction probabilities of sulfate and nitrate precursors onto East Asian dust particles, J. Geophy. Res., 112, D18206, doi:10.1029/2006JD008092, 2007.

Song, C. H., Park, M. E., Lee, K. H., Ahn, H. J., Lee, Y., Kim, J. Y., Han, K. M., Kim, J., Ghim, Y. S., and Kim, Y. J.: An investigation into seasonal and regional aerosol characteristics in East Asia using model-predicted and remotely-sensed aerosol properties, Atmos. Chem. Phys., 8, 6627-6654, doi:10.5194/acp8-6627-2008, 2008.

Song, Q., Cornillon, P., and Hara, T.: Surface wind response to oceanic fronts, J. Geophys. Res., 111, C12006, doi:10.1029/2006JC003680, 2006.

Sugimoto, N., Matsui, I., Shimizu, A., and Nishizawa, T.: LiDAR network for monitoring Asian dust and air pollution aerosols, IGARSS 2008, 573-576, 2008.

Sugimoto, N., Uno, I., Nishikawa, M., Shimizu, A., Matsui, I., Dong, X., Chen, Y., and Quan, H.: Record heavy Asian dust in Beijing in 2002: Observations and model analysis of recent events, Geophys. Res. Lett., 30, 1640, doi:10.1029/2002GL016349, 2003.

Tegen, I., Lacis, A. A., and Fung, I. Y.: The influence of mineral aerosol from disturbed soils on the global radiation budget, Nature, 380, 419-422, 1996.

Twomey, S. A., Piepgrass, M., and Wolfe, T. L.: An assessment of the impact of pollution on global cloud albedo, Tellus, 36, 356366, 1984.

Uno, I., Wang Z., Chiba M., Chun Y. S., Gong S. L., Hara Y., Jung E., Lee S.-S., Liu M., Mikami M., Music S., Nickovic S., Satake S., Shao Y., Song Z., Sugimoto N., Tanaka T., and Westphal D. L.: Dust model intercomparison (DMIP) study over Asia: Overview, J. Geophys. Res., 111, D12213, doi:10.1029/2005JD006575, 2006.

van Donkelaar, A., Martin, R. V., and Park, R. J.: Estimating ground-level PM2.5 using aerosol optical thickness determined from satellite remote sensing, J. Geophys. Res., 111, D21201, doi:10.1029/2005JD006996, 2006.

Velotta, R., Bartoli, B., Capobianco, R., and Spinelli, N.: Analysis of the receiver response in lidar measurements, Appl. Opt., 37, 6999-7007, 1998.

Vidot, J., Ramon, D., and Santer, R.: Atmospheric particulate matter (PM) estimation from SeaWiFS imagery, Remote Sens. Environ., 111, 1-10, 2007. 
Wang, J. and Christopher, S. A.: Intercomparison between satellitederived aerosol optical thickness and $\mathrm{PM}_{2.5}$ mass: Implications for air quality studies, Geophys. Res. Lett., 30, 2095, doi:10.1029/2003GL018174, 2003.

Yu, H., Dickinson, R. E., Chin, M., Kaufman, Y. J., Holben, B. N., Geogdzhayev, I. V., and Mishchenko, M. I.: Annual cycle of global distributions of aerosol optical depth from integration of MODIS retrievals and GOCART model simulations, J. Geophys. Res., 108, 4128, doi:10.1029/2002JD002717, 2003.

Zhang, D., Zang, J., Shi, G., Iwasaka, Y., Matsuki, A., and Trochkine, D.: Mixture state of individual Asian dust particles at a coastal site of Qingdao, China, Atmos. Environ., 37, 38953901, 2003.
Zhang, Q., Streets, D. G., He, K., Wang, Y., Richter, A., Burrows, J. P., Uno, I., Jang, C. J., Chen, D., Yao, Z., and Lei, Y.: $\mathrm{NO}_{\mathrm{X}}$ emission trends for China, 1995-2004: The view from the ground and the view from space, J. Geophys. Res, 112, D22306, doi:10.1029/2007JD008684, 2007.

Zhou, M., Okada, K., Qian, F., Wu, P.-M., Su, L., Casareto, B. E., and Shimohara, T.: Characteristics of dust-storm particles and their long-range transport from China to Japan-case studies in April 1993, Atmos. Res., 40, 19-31, 1996. 